\title{
Flavonoids as positive allosteric modulators of $\alpha 7$ nicotinic receptors
}

Beatriz Elizabeth Nielsen ${ }^{1}$, Isabel Bermudez ${ }^{2}$ and Cecilia Bouzat ${ }^{1}$

${ }^{1}$ Instituto de Investigaciones Bioquímicas de Bahía Blanca, Departamento de Biología, Bioquímica y Farmacia, Universidad Nacional del Sur-Consejo Nacional de Investigaciones Científicas y Técnicas (CONICET), Bahía Blanca 8000, Argentina.

${ }^{2}$ Department of Medical and Biological Sciences, Oxford Brookes University, Oxford OX3 OBP, United Kingdom.

Correspondence to: Dr. Cecilia Bouzat. Instituto de Investigaciones Bioquímicas de Bahía Blanca, UNS-CONICET, Bahía Blanca 8000, Argentina., E-mail: inbouzat@criba.edu.ar

\section{ABBREVIATIONS}

PAM: positive allosteric modulator

nAChR: nicotinic acetylcholine receptor

ACh: acetylcholine

pLGIC: pentameric ligand-gated ion channel

Neo: neoflavonoid 5,7-dihydroxy-4-phenylcoumarin

TMD: transmembrane domain

ECD: extracellular domain

Gen: genistein

Que: quercetin

5-HI: 5-hydroxyindole

PNU-120596: N-(5-Chloro-2,4-dimethoxyphenyl)-N'-(5-methyl-3-isoxazolyl)-urea PNU-282987: N-[(3R)-1-Azabicyclo[2.2.2]oct-3-yl]-4-chlorobenzamide hydrochloride NS-1738: N-(5-Chloro-2-hydroxyphenyl)-N'-[2-chloro-5-(trifluoromethyl)phenyl]urea ROS: reactive oxygen species

DCFDA: 2',7'-dichlorofluorescein diacetate $\alpha$-Bgt: $\alpha$-bungarotoxin 


\section{ABSTRACT}

The use of positive allosteric modulators (PAM) of $\alpha 7$ nicotinic receptors is a promising therapy for neurodegenerative, inflammatory and cognitive disorders. Flavonoids are polyphenolic compounds showing neuroprotective, anti-inflammatory and pro-cognitive actions. Besides their well-known antioxidant activity, flavonoids trigger intracellular pathways and interact with receptors, including $\alpha 7$. To reveal how the beneficial actions of flavonoids are linked to $\alpha 7$ function, we evaluated the effects of three representative flavonoids -genistein, quercetin and the neoflavonoid 5,7-dihydroxy-4-phenylcoumarinon whole-cell and single-channel currents. All flavonoids increase the maximal currents elicited by acetylcholine with minimal effects on desensitization and do not reactivate desensitized receptors, a behaviour consistent with type I PAMs. At the single-channel level, they increase the duration of the open state and produce activation in longduration episodes with a rank order of efficacy of genistein $>$ quercetin $\geq$ neoflavonoid. By using mutant and chimeric $\alpha 7$ receptors, we demonstrated that flavonoids share transmembrane structural determinants with other PAMs. The $\alpha 7-P A M$ activity of flavonoids results in decreased cell levels of reactive oxygen species. Thus, allosteric potentiation of $\alpha 7$ may be an additional mechanism underlying neuroprotective actions of flavonoids, which may be used as scaffolds for designing new therapeutic agents.

\section{KEY WORDS}

nicotinic receptor

patch-clamp

single-channel recordings

flavonoids

Cys-loop receptors 


\section{INTRODUCTION}

The $\alpha 7$ nicotinic acetylcholine receptor $(n A C h R)$ is one of the most abundant $n A C h R s$ in the brain and is a promising drug target for neurological, neurodegenerative, inflammatory and cognitive disorders. It is a pentameric neurotransmitter-gated ion channel (pLGIC) that contains an extracellular domain (ECD), which carries the agonist binding sites at subunit interfaces; a transmembrane domain (TMD), which comprises the pore and it is formed by four $\alpha$-helices of each subunit (TM1-TM4); and an intracellular domain. Between ECD and TMD there is a structural transition zone that is essential to couple agonist binding to channel opening (Bouzat et al., 2004). $\alpha 7$ responds to acetylcholine (ACh) by opening an intrinsic ion channel which triggers rapid membrane depolarization and calcium influx (Dajas-Bailador and Wonnacott, 2004). It also triggers signal transduction pathways and the release of calcium from intracellular stores (Bouzat et al., 2018; Corradi and Bouzat, 2016; Egea et al., 2015; Guan et al., 2015; Kabbani and Nichols, 2018). $\alpha 7$ is highly expressed in hippocampus, cortex and several subcortical limbic regions; and it is involved in cognition, sensory processing information, attention, and working memory (Lendvai et al., 2013; Thomsen et al., 2010; Uteshev, 2014). Decline of $\alpha 7$ activity has been associated with Alzheimer's disease and schizophrenia (Buckingham et al., 2009; Dineley et al., 2015; Guan et al., 2000; Kadir et al., 2006; Kalmady et al., 2018; Ma and Qian, 2019; Thomsen et al., 2010; Tregellas and Wylie, 2019). $\alpha 7$ is also present in non-neuronal cells, where it plays a key role in immunity, inflammation and neuroprotection (Dineley et al., 2015; Egea et al., 2015; Park et al., 2007; Shen and Yakel, 2012; Shytle et al., 2004).

Enhancement of $\alpha 7$ activity is therefore emerging as a therapeutic strategy for neurological and inflammatory disorders (Changeux and Taly, 2008; Corradi and Bouzat, 2016; Dineley et al., 2015; Uteshev, 2014). Positive allosteric modulators (PAMs) are promising therapeutic tools because they maintain the temporal and spatial characteristics of the endogenous activation and are more selective than agonists (Bouzat et al., 2018; Chatzidaki and Millar, 2015; Corradi and Bouzat, 2016; Yang et al., 2017). Based on their effects on macroscopic currents, PAMs have been classified as type I PAMs, that mainly enhance agonist-induced peak currents; and type II PAMs, that also decrease desensitization and recover receptors from desensitized states (Bertrand and Gopalakrishnan, 2007; Chatzidaki and Millar, 2015).

On the other hand, there is increasing epidemiological and experimental data showing that dietary intake of flavonoids confers protection against multiple chronic diseases, improves cognitive performance and reduces the incidence of age-related 
neurological decline (Bakoyiannis et al., 2019; Ebrahimi and Schluesener, 2012;

Flanagan et al., 2018; Gildawie et al., 2018; Spencer et al., 2009; Vauzour et al., 2015). Flavonoids are potent antioxidant and anti-inflammatory agents and have shown neuroprotective effects in vitro and in vivo (Bakhtiari et al., 2017; Dajas et al., 2013; Spencer et al., 2012; Vauzour et al., 2015). Consequently, they are considered as potentially beneficial for age-related phenomena and neurodegenerative diseases, including Alzheimer's and Parkinson's diseases (Bakhtiari et al., 2017; Bakoyiannis et al., 2019; Ebrahimi and Schluesener, 2012; Kujawska and Jodynis-Liebert, 2018; Rossi et al., 2008; Spencer et al., 2012).

Flavonoids are polyphenolic compounds ubiquitously present in plants. They are derivatives of 2-phenyl-benzo- $y$-pyrone, consisting in a 15-carbon skeleton that comprises two phenyl rings ( $\mathrm{A}$ and $\mathrm{B}$ ), linked together by an oxygen-containing pyrone ring (C) (Fig. 1A). According to the IUPAC, flavonoids are classified into flavonoids, isoflavonoids and neoflavonoids depending on the position of the B-ring in the benzopyrone moiety (Heim et al., 2002) (Fig. 1A). On the basis of the oxidation state of the C-ring, the hydroxylation pattern, and the substitution of the 3-position, flavonoids are also grouped into six subclasses named as flavanols, flavanones, flavones, isoflavones, flavonols and anthocyanins (Corcoran et al., 2012; Panche et al., 2016).

Some benefits of flavonoids have been mainly atributted to their antioxidant capacity that includes direct effects (free radical scavenging and metal chelating activities) and indirect effects (modulating enzymes such as xanthine oxidase and nitric oxide synthase) (Dajas et al., 2013). However, flavonoids also exert other effects that reinforce their antioxidant and neuroprotective role, including modulation of signalling pathways, transcription factors and gene expression (Bakhtiari et al., 2017; Bakoyiannis et al., 2019; Dajas et al., 2013; Ebrahimi and Schluesener, 2012; Flanagan et al., 2018; Spencer et al., 2012; Vauzour et al., 2015; Williams et al., 2004). Moreover, in vivo beneficial effects of flavonoids take place at lower doses than those required for their direct antioxidant activity, indicating that additional mechanisms involving signalling processes may be implicated in their actions (Dajas et al., 2013; Flanagan et al., 2018; Spencer et al., 2012; Williams et al., 2004). Among these processes, flavonoids have been shown to directly modulate neurotransmitter receptors and ion channels (Goutman et al., 2003; Hanrahan et al., 2011; Huang et al., 1999; Huang and Dillon, 2000; Johnston, 2015; Lee et al., 2007, 2005; Shin et al., 2010).

There are a few reports regarding their effects on $\alpha 7$, specifically showing that genistein and quercetin enhance the macroscopic currents of $\alpha 7$ elicited by ACh (Grønlien et al., 2007; Lee et al., 2010). Interestingly, the positive modulatory effects of 
flavonoids seems to be specific for $\alpha 7$ among pLGICs since genistein inhibits $\mathrm{GABA}_{\mathrm{A}}$ (Huang et al., 1999), glycine (Huang and Dillon, 2000), 5- $\mathrm{HT}_{3} \mathrm{~A}, \alpha 4 \beta 2$ and $\alpha 3 \beta 4$ receptors (Grønlien et al., 2007); and quercetin inhibits 5- $\mathrm{HT}_{3} \mathrm{~A}$ (Lee et al., 2008, 2005),

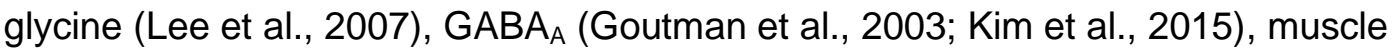
nAChR (Lee et al., 2011c), $\alpha 3 \beta 4$ (Lee et al., 2011b), $\alpha 4 \beta 2$ (Goutman et al., 2003), and $\alpha 9 \alpha 10$ receptors (Lee et al., 2011a).

Even though $\alpha 7$ cholinergic signalling and flavonoids are both clearly involved in cognition, memory and neuroprotection as well as in the modulation of inflammatory processes, only a few studies have focused on the molecular mechanisms underlying the effects of these polyphenolic compounds on $\alpha 7$ activity.

Here by using whole-cell and single-channel current approaches combined with mutagenesis, we have deciphered the molecular modulation of human $\alpha 7$ by flavonoids with distinct position of the B-ring in the benzopyrone moiety: the isoflavone genistein and the flavonol quercetin, previously reported as $\alpha 7-P A M s$ (Grønlien et al., 2007; Lee et al., 2010), and the neoflavonoid 5,7-dihydroxy-4-phenylcoumarin, whose activity on $\alpha 7$ is unknown. We have also demonstrated that the $\alpha 7-P A M$ activity of flavonoids constitutes a novel and additional molecular mechanism by which they exert their antioxidant and neuroprotective role.

Overall, by providing novel information on $\alpha 7$ potentiation by flavonoids, our study contributes to the understanding of the mechanisms of their biological activities as well as their clinical relevance. Potentiation of $\alpha 7$ implies an additional process by which these polyphenols may be beneficial for neurological and inflammatory disorders. 


\section{MATERIALS AND METHODS}

2.1. Drugs. Acetylcholine, 5 -hydroxyindole (5-HI) and 5,7-dihydroxy-4phenylcoumarin were purchased from Sigma-Aldrich (St Louis, MO, USA). PNU120596 (N-(5-chloro-2,4-dimethoxyphenyl)-N'-(5-methyl-3-isoxazolyl)-urea) was obtained from Tocris Biosciences (Bristol, UK). PNU-282987 [N-[(3R)-1azabicyclo[2.2.2]oct-3-yl]-4-chlorobenzamide hydrochloride], NS-1738 (N-(5-chloro-2hydroxyphenyl)-N'-[2-chloro-5-(trifluoromethyl)phenyl]urea), genistein (4',5,7trihydroxyisoflavone) and quercetin (2-(3,4-dihydroxyphenyl)-3,5,7-trihydroxychromen4-one) were purchased from Santa Cruz Biotechnology (Dallas, Texas, USA). $\alpha$ bungarotoxin ( $\alpha$-Bgt) was from ThermoFisher Scientific (MA, USA). Stock solutions were prepared in water (ACh, 5-HI and $\alpha$-Bgt) or DMSO (PNU-120596, NS-1738 and flavonoids).

\subsection{Expression of $\alpha 7$ receptors in Xenopus laevis oocytes. Adult female} Xenopus laevis were purchased from Nasco (WI, USA). Xenopus care and experimental procedures were in accordance with the UK Home Office regulations and were approved by the Animal Use Committee of Oxford Brookes University. Stage V and VI Xenopus oocytes were prepared as previously described (Carbone et al., 2009; Mazzaferro et al., 2011), and then injected with 2-20 ng of human $\alpha 7$ subunit cDNA (GenBank accession no X70297.1) into the nucleus in a volume of $23.0 \mathrm{~nL}$, using a Nanoject Automatic Oocyte Injector (Drummond, Broomall, USA). To favour the fast expression of $\alpha 7$, its cDNA was co-injected with 1-2 ng of chaperone NACHO cDNA (GenBank accession no BC050273.1) (Gu et al., 2016; Nielsen et al., 2018). Injected oocytes were incubated until use at $18^{\circ} \mathrm{C}$ in Barth's solution $(88 \mathrm{mM} \mathrm{NaCl}, 1 \mathrm{mM} \mathrm{KCl}$, $0.33 \mathrm{mM} \mathrm{Ca}\left(\mathrm{NO}_{3}\right)_{2}, 0.41 \mathrm{mM} \mathrm{CaCl}_{2}, 0.82 \mathrm{mM} \mathrm{MgSO}_{4}, 2.4 \mathrm{mM} \mathrm{NaHCO}_{3}, 10 \mathrm{mM}$ HEPES) supplemented with $0.1 \mathrm{mg} / \mathrm{mL}$ streptomycin, $1000 \mathrm{U} / \mathrm{mL}$ Penicillin and 100 $\mu \mathrm{g} / \mathrm{mL}$ amikacin ( $\mathrm{pH} 7.5$ with $5 \mathrm{M} \mathrm{NaOH}$ ). Oocytes were used for electrophysiological recordings one to two days after injection (Carbone et al., 2009; Mazzaferro et al., 2011; Nielsen et al., 2018).

2.3. Electrophysiological recordings in Xenopus laevis oocytes. Oocytes were impaled by two microelectrodes filled with $3 \mathrm{M} \mathrm{KCl}(0.5-2.0 \mathrm{M} \Omega)$ and voltage-clamped at $-60 \mathrm{mV}$ using HiClamp, an automated two-electrode voltage-clamp recording system (Multi Channel Systems, Reutlingen, Germany) (Rego Campello et al., 2018). Data were captured and analyzed with Data Mining software (Multi Channel Systems, Reutlingen, Germany). All experiments were carried out at room temperature. The 
oocytes were continuously perfused by Standard Oocyte Solution (SOS) containing $100 \mathrm{mM} \mathrm{NaCl}, 2 \mathrm{mM} \mathrm{KCl}, 1.8 \mathrm{mM} \mathrm{CaCl}_{2}, 1 \mathrm{mM} \mathrm{MgCl}_{2}$ and $5 \mathrm{mM} \mathrm{HEPES}$ (pH 7.4 with 5 $\mathrm{M} \mathrm{NaOH})$. ACh was dissolved directly in SOS. The experimental flavonoid solutions were prepared from the stock solution with a final DMSO concentration lower than 0.8 $\%$ (v/v). We have previously shown that DMSO concentrations below $1 \%$ do not affect $\alpha 7$ activation properties (Andersen et al., 2016, 2013). The recordings were performed in different oocytes ( $\mathrm{n}$ indicates the number of independent experiments) and for each condition, at least three different batches of oocytes from distinct Xenopus laevis animals were used for experiments ( $\mathrm{N}$ indicates the number of batches of oocytes).

To study the activity of different flavonoids, responses were evaluated following co-application and preincubation protocols. Flavonoids were co-applied with ACh at a concentration close to its $\mathrm{EC}_{20}(30 \mu \mathrm{M})$ for $\alpha 7$ receptor as described previously (Nielsen et al., 2018). The peak current responses were normalized to the responses elicited by $\mathrm{ACh} \mathrm{EC}_{20}$ alone in the same oocyte (control current). A control current was elicited before and after each current in presence of agonist and flavonoid. For all the conditions, a 3-minute wash period allowed a total recovery of control currents. Concentration-response curves for flavonoids were fitted by a non-linear least-squares algorithm according to the equation:

$$
I=\operatorname{Imax} /\left[1+\left(E C_{50} / x\right)^{n}\right]
$$

in which $I_{\max }$ is the maximum obtainable peak current; $\mathrm{EC}_{50}$ is the concentration of the agonist and flavonoid that elicits $50 \%$ of the maximum obtainable peak current; $x$ is flavonoid concentration and $\mathrm{n}$ is the slope factor.

2.4. Expression of $\alpha 7$ in BOSC23 cells. Receptors were transiently expressed in BOSC23 cells, which are modified HEK 293T cells (kindly provided by Dr. Sine, Mayo Clinic, USA). To discard mycoplasma contamination, cells were tested by 4,6Diamidino-2-phenylindole (DAPI) staining and fluorescence microscopy. The receptors were human $\alpha 7$ wild-type ( $\alpha 7$ WT); human $\alpha 7$ quintuple mutant ( $\alpha 7$ TSLMF), which carries five point mutations in the transmembrane domain (S223T, A226S, M254L, I281M and V288F) (DaCosta et al., 2011) and is insensitive to PNU-120596; and the high conductance form of the chimeric receptor containing the extracellular domain of human $\alpha 7$ and the transmembrane domain of the mouse $5-\mathrm{HT}_{3} \mathrm{~A}$ receptor $\left(\alpha 7-5 \mathrm{HT}_{3} \mathrm{~A}\right)$ (Bouzat et al., 2004). Cells were transfected by calcium phosphate precipitation with the subunit cDNAs alone or together with the chaperone Ric-3 cDNA (GenBank accession no. NM_024557.5) for $\alpha 7$ WT and $\alpha 7$ TSLMF (Andersen et al., 2013; Bouzat et al., 2008; Nielsen et al., 2018). GFP cDNA was incorporated during transfection (5\% 
of total cDNA amount) to allow identification of transfected cells in green. All transfections were carried out for about 8-12 hours in DMEM (Gibco) with $10 \%$ FBS (Internegocios) and were terminated by exchanging the medium. Cells were used for whole-cell and single-channel recordings two to three days after transfection at which time maximum functional expression levels are usually achieved (Andersen et al., 2016; Bouzat et al., 2008, 1994; DaCosta et al., 2015, 2011; Nielsen et al., 2018).

2.5. Whole-cell recordings from BOSC23 cells. Macroscopic currents were recorded in the whole-cell configuration at $-50 \mathrm{mV}$ as described previously (Andersen et al., 2016; Bouzat et al., 2008; Corradi et al., 2009). The pipette was filled with intracellular solution (ICS) containing $134 \mathrm{mM} \mathrm{KCl,} 5 \mathrm{mM} \mathrm{EGTA}, 1 \mathrm{mM} \mathrm{MgCl}$, and 10 mM HEPES (pH 7.3). The extracellular solution (ECS) contained $150 \mathrm{mM} \mathrm{NaCl}, 1.8$ $\mathrm{mM} \mathrm{CaCl}_{2}, 1 \mathrm{mM} \mathrm{MgCl}_{2}$, and $10 \mathrm{mM}$ HEPES (pH 7.3). Agonist responses (control currents) were obtained by a pulse of ECS containing the agonist. The PAMs and flavonoids were dissolved in ECS from DMSO stock solutions. The final concentration of DMSO used to solubilize PAMs and flavonoids was lower than $0.1 \%(\mathrm{v} / \mathrm{v})$.

Responses were evaluated following co-application protocols, where a 1.5-s pulse of ECS containing ACh and flavonoid was applied. The duration of the recording was $2.0 \mathrm{~s}$. For all conditions, an 8-s wash period allowed total recovery of control currents. The temporal parameters were selected considering the typical kinetics of $\alpha 7$ macroscopic currents in BOSC23 cells (Andersen et al., 2016; Corradi et al., 2009; DaCosta et al., 2011).

To evaluate the recovery of desensitized receptors by flavonoids or other PAMs, ACh was applied continuously for a 3.0-s period; $1.2 \mathrm{~s}$ after the beginning of the ACh-pulse, the tested compound was simultaneously applied during the remaining 1.8 $s$ in order to show the effects on desensitized receptors. In all cases, an 8-s wash period allowed total recovery of control currents.

The solution exchange time was estimated by the open pipette protocol and ranged from 0.1 to $1.0 \mathrm{~ms}$ (Andersen et al., 2016; Corradi et al., 2009). Currents were filtered at $5 \mathrm{kHz}$ and digitized at $20 \mathrm{kHz}$ using an Axopatch 200B patch-clamp amplifier (Molecular Devices, CA, USA) and acquired using WinWCP software (Strathclyde Electrophysiology Software, University of Strathclyde, Glasgow, UK). The recordings were analysed using the ClampFit software (Molecular Devices, CA, USA). Each current represents the average from three to five individual traces obtained from the same cell, which were aligned with each other at the maximum peak. Currents were fitted by a double exponential function according to the equation: 


$$
I(t)=I_{\text {fast }}\left[\exp \left(-t / \tau_{\text {fast }}\right)\right]+I_{\text {slow }}\left[\exp \left(-t / \tau_{\text {slow }}\right)\right]+I_{\infty}
$$

in which $t$ is time, $I_{\text {fast }}$ and $I_{\text {slow }}$ are the amplitude for each component, $I_{\infty}$ is the steady state current value, and $\tau_{\text {fast }}$ and $\tau_{\text {slow }}$ are the fast and slow decay time constants, respectively. The net charge was calculated by current integration (Papke and Papke, 2002). $\tau_{\text {fast }}$ and $\tau_{\text {slow }}$ were expressed as absolute values because these constants are independent of the expression level of $\alpha 7$ in each cell. In contrast, the peak current and the net charge responses were normalized to the responses elicited by ACh in the same cell (control currents) because they vary with the expression level of $\alpha 7$.

2.6. Single-channel recordings in BOSC23 cells. Single channels were recorded in the cell-attached patch configuration (Bouzat et al., 2008). Each patch corresponds to a distinct cell ( $\mathrm{n}$ indicates the number of independent experiments). For each condition (different receptors or drugs), three or more cell transfections from distinct days were performed for the recordings ( $\mathrm{N}$ indicates the number of cell transfections).

For $\alpha 7$ WT and quintuple mutant, the bath and pipette solutions contained 142 $\mathrm{mM} \mathrm{KCl}, 5.4 \mathrm{mM} \mathrm{NaCl}, 1.8 \mathrm{mM} \mathrm{CaCl}_{2}, 1.7 \mathrm{mM} \mathrm{MgCl}_{2}$ and $10 \mathrm{mM} \mathrm{HEPES} \mathrm{(pH} \mathrm{7.4).}$ Only for the chimeric receptor $\alpha 7-5 \mathrm{HT}_{3} \mathrm{~A}$, the bath and pipette solutions were free of magnesium and with low-calcium concentration $\left(0.2 \mathrm{mM} \mathrm{CaCl}_{2}\right)$, in order to minimize channel block by divalent cations as previously described (Andersen et al., 2016; Rayes et al., 2005). Flavonoids $(5-100 \mu \mathrm{M})$ were added to the pipette solution with ACh. Thus, single channel activity was recorded in the continuous presence of the drugs. The typical recording time was between 5 and 10 minutes. The final concentration of DMSO used to solubilize flavonoids was lower than $0.1 \%(\mathrm{v} / \mathrm{v})$. This DMSO concentration does not affect $\alpha 7$ activation properties (Andersen et al., 2016, 2013). ACh was solubilized directly in the pipette solution. Single-channel currents were digitized at 5-10 $\mu$ s intervals and low-pass filtered at a cut-off frequency of $10 \mathrm{kHz}$ using an Axopatch 200B patch-clamp amplifier (Molecular Devices, CA, USA). The single-channel currents were recorded at $-70 \mathrm{mV}$ membrane potential that allows a good signal-to-noise ratio. Analysis was performed with the program TAC (Bruxton Corporation, Seattle, WA, USA) with the Gaussian digital filter at $9 \mathrm{kHz}$ (Final cut-off frequency $6.7 \mathrm{kHz}$ ). Events were detected by the half-amplitude threshold criterion (Bouzat et al., 2004). To determine channel amplitude, events were tracked regardless of current amplitude and amplitude histograms were then constructed. Open-time histograms were fitted by the sum of exponential functions by maximum likelihood using the program TACFit (Bruxton Corporation, Seattle, WA, USA). Bursts of channel openings were identified as a series of closely separated openings preceded and 
followed by closings longer than a critical duration, which was taken as the point of intersection between closed components as previously described (Andersen et al., 2016, 2013; Bouzat et al., 2008; Nielsen et al., 2018). Critical durations were defined by the intersection between the first and second briefest components in the closed-time histogram for bursts of $\alpha 7$ ( 200-400 $\mu$ s) and second and third closed components for bursts of $\alpha 7$ TSLMF ( 1-4 ms) and $\alpha 7-5 \mathrm{HT}_{3} \mathrm{~A}$ ( 2-5 ms), activated by ACh alone. In presence of flavonoids, the critical time was defined between the second and the third closed components for bursts of $\alpha 7$ ( 1-5 ms). For $\alpha 7$ TSLMF and $\alpha 7-5 \mathrm{HT}_{3} \mathrm{~A}$, the critical times did not show differences in absence or presence of flavonoids together with ACh. The longest duration closed components from the closed-time histograms were not analyzed because of their intrinsic variability that depends on the expression level of $\alpha 7$ in each cell.

\subsection{Measurement of Reactive Oxygen Species (ROS) production. BOSC23}

cells transiently expressing human $\alpha 7$ WT were seeded at $3 \times 10^{4}$ cells per well in clearbottom, black walled, 96-well plates (Nunc, 165305, Thermo Fisher Scientific) previously coated with Poly-L-ornithine (Sigma Aldrich, St Louis, MO, USA) and allowed to attach to the bottom of the wells for $24 \mathrm{~h}$. Then, cells were exposed to different treatments (agonist, $\alpha$-Bgt, flavonoids and distinct combinations) for additional 12 or $24 \mathrm{~h}$ in DMEM free of FBS. $\alpha$-Bgt was added $2 \mathrm{~h}$ before the other compounds to allow complete blockade of $\alpha 7$. Subsequently, the cells were washed twice with PBS and incubated with $10 \mu \mathrm{M}$ 2',7'-Dichlorofluorescein diacetate (DCFDA) (Santa Cruz Biotechnology, Dallas, Texas, USA) for 20 minutes at $37^{\circ} \mathrm{C}$. After incubation, loaded cells were washed twice with PBS. The DCF fluorescence intensity is proportional to the amount of ROS generated intracellularly (LeBel et al., 1992).

Fluorescence images were acquired with a Nikon Eclipse TE 2000 fluorescence microscope (Nikon Instruments Inc., Melville, USA). The fluorescence intensity was measured by a microplate reader (Fluroskan Ascent FL, Thermo Scientific) at an excitation wavelength of $485 \mathrm{~nm}$ and an emission wavelength of $538 \mathrm{~nm}$. The signals were acquired at $1 \mathrm{~min}$-intervals over a period of $30 \mathrm{~min}$ (Bian et al., 2015). Since DCF can produce artifactual signal amplification upon light exposure by oxidation, normalization dividing by fluorescence at time zero is not appropriate. Thus, the rate of ROS increment as a function of time was calculated because this rate is solely described by the level of cellular ROS (Koopman et al., 2006; Sepúlveda et al., 2013). During the kinetic assay, dye controls (probe solution alone) and positive controls (adding $1 \mathrm{mM} \mathrm{H}_{2} \mathrm{O}_{2}$ to control loaded cells) were assessed in order to verify the correct 
performance of the probe (Bian et al., 2015; Sepúlveda et al., 2013). All assays were performed in at least three individual experiments, each comprising three to six replicates.

2.8. Statistical analysis. Data are presented as mean \pm SEM or mean $\pm S D$ as appropriate. Data sets that passed the Shapiro-Wilk test for normality and the Levene Median test for equal variance were analysed using two-tailed Student's t-test for pairwise comparisons or OneWay ANOVA followed by Bonferroni's post-hoc tests for multiple comparisons. All the tests were performed with SigmaPlot 12.0 (Systat Software, Inc.). Statistically significance differences were established at $p$-values $<0.05$ $\left(p<0.05^{*}, p<0.01^{* *}, p<0.001^{* * *}\right)$. When post-hoc tests were applied, the $p$-values for the comparison among groups were indicated in the corresponding Figures or Tables. The number of independent experiments $(n)$ and the number of batches of oocytes or cell transfections $(\mathrm{N})$ were indicated in the Tables or under Results.

Concentration-response curves were determined by nonlinear regression fits to the Hill equation using Prism 5.0 (GraphPad, San Diego, CA). ROS production curves were fitted by linear regression using Prism 5.0 (GraphPad, San Diego, CA). 


\section{RESULTS}

\subsection{Flavonoids enhance ACh-induced macroscopic currents recorded from Xenopus laevis oocytes expressing $\alpha 7$.}

The effects of representative flavonoids from distinct classes differing in the position of the B-ring in the benzopyrone moiety were first assessed in oocytes expressing human $\alpha 7$ : quercetin as a flavonol (B-ring in position 2, flavonoid group), genistein as an isoflavone (B-ring in position 3, isoflavonoid group), and 5,7-dihydroxy4-phenylcoumarin as a neoflavonoid (B-ring in position 4, neoflavonoid group). For convenience, we referred to these compounds as Que, Gen and Neo, respectively (Fig. $1 \mathrm{~A})$.

In the presence of ACh, a large inward current was detected in oocytes expressing human $\alpha 7$, whereas no currents were detected from oocytes injected with 1-2 ng of NACHO cDNA alone ( $n=17)$. Co-application of Gen, Que or Neo with $30 \mu \mathrm{M}$ ACh enhanced the macroscopic currents evoked by ACh in a concentration-dependent manner (Table 1, Fig 1A). Full decay of $\alpha 7$ currents either in the absence or presence of the flavonoids occurred during the duration of the pulse (20 s) (Fig. 1A).

Preincubation of the oocytes with the flavonoid solution for $10 \mathrm{~s}$ before the coapplication step also induced potentiation of the ACh-elicited currents by the three flavonoids in a concentration-dependent manner. During the preincubation time with flavonoids alone, currents were not evoked at any of the concentrations tested, thus discarding an agonist role for these compounds.

We generated concentration-response curves for the flavonoids applied under the two protocols, co-application with and without preincubation (Fig. 1B). The results showed that the three types of flavonoids have a7-PAM activity, which was evidenced by a statistically significant increase of the peak currents evoked by ACh ( 1.5 - 2-fold) (Gen $[\mathrm{t}(20)=-39.799, \mathrm{p}<0.001$ for co-application and $\mathrm{t}(30)=-94.400, \mathrm{p}<0.001$ for preincubation + co-application], Que $[t(14)=-45.659, p<0.001$ for co-application and $t(14)=-26.264, p<0.001$ for preincubation + co-application $]$ and $\mathrm{Neo}[t(18)=-48.488$, $\mathrm{p}<0.001$ for co-application and $\mathrm{t}(16)=-67.500, \mathrm{p}<0.001$ for preincubation $+\mathrm{co}$ application]) (Fig. 1B and Table 1).

There were no statistically significant differences in the $\mathrm{EC}_{50}$ values $[\mathrm{t}(25)=-$ 0.617, $p=0.543$ for Gen, $t(14)=1.330, p=0.205$ for Que and $t(17)=0.526, p=0.606$ for $\mathrm{Neo}]$ and in the degree of potentiation $[\mathrm{t}(25)=-1.095, \mathrm{p}=0,284$ for Gen, $\mathrm{t}(14)=-1.053$, $p=0.310$ for Que and $t(17)=0.231, p=0.820$ for Neo], for each flavonoid between the two protocols thus indicating that co-application with the agonist is sufficient for 
flavonoid activity. The rank order of potency for potentiation in the co-application protocol was Gen Neo $>$ Que $[F(2)=7.614, p=0.002<0.01]$. With the preincubation protocol, $E_{50}$ values did not show significant differences $[F(2)=1.699, p=0.200]$. Therefore, we conclude that the rank order of potency among flavonoids was Gen Neo $\geq$ Que (Table 1).

The rank order of efficacy, measured by the increase in the peak currents, was Gen $>$ Que $\sim$ Neo for both protocols $[F(2)=28.276, p<0.001$ for co-application and $F(2)=33.958, p<0.001$ for preincubation + co-application] (Table 1).

Together, these findings indicate that the three types of flavonoids increase the current amplitude elicited by the agonist, consistent with their actions as PAMs (Bertrand and Gopalakrishnan, 2007; Bouzat et al., 2018; Chatzidaki and Millar, 2015; Faghih et al., 2008; Williams et al., 2011).

\subsection{Flavonoids act as type I PAMs of $\alpha 7$ expressed in mammalian cells.}

To determine whether flavonoids behave as PAM type I or II, we determined their effects on the desensitization of $\alpha 7$ receptors expressed in BOSC23 cells. While oocytes are ideal for drug screening, they are not suitable for determining desensitization rates for receptors that show fast kinetics, such as $\alpha 7$. Due to their smaller size, mammalian cells allow higher temporal resolution, which in turn leads to a more accurate determination of the kinetic parameters (Corradi and Bouzat, 2016).

Rapid application of ACh to BOSC23 cells expressing human $\alpha 7$ elicited macroscopic currents that reached the peak in about 5-10 ms and decayed in the presence of the agonist due to desensitization. Current decays were fitted by two exponential components, $\tau_{\text {fast }}(\sim 30-50 \mathrm{~ms})$ and $\tau_{\text {slow }}(\sim 500-1000 \mathrm{~ms})$.

The distinct effects of a typical type I PAM (5-HI, (Zwart et al., 2002)) and type II PAM (PNU-120596, (Hurst et al., 2005)) were clearly distinguished from ACh-elicited macroscopic currents. 5 - $\mathrm{HI}$ increased significantly only peak currents whereas PNU120596 also decreased current decay rates (Fig. 2A).

To test flavonoids on whole-cell currents, we chose a concentration of $50 \mu \mathrm{M}$ based on the concentration-response curves in Xenopus oocytes showing maximal activity at this concentration. Macroscopic currents recordings were performed by coapplying agonist and flavonoids for two main reasons. First, there were no differences in the maximal effects of flavonoids on Xenopus oocytes between both protocols (preincubation plus co-application or co-application alone). Second, since Gen and Que can act as tyrosine kinase inhibitors, co-application of flavonoids and ACh reduces 
the time needed for kinase inhibition and therefore the possibility of modifying the phosphorylation state of the receptor (Grønlien et al., 2010, 2007; Huang et al., 1999; Huang and Dillon, 2000).

In the presence flavonoids $(50 \mu \mathrm{M})$, the maximal currents elicited by $100 \mu \mathrm{M}$ ACh increased but the decay time constants did not show any statistically significant change (Fig. 2A, Table 1), which confirmed that they are type I PAMs, in agreement with previous reports for Gen (Grønlien et al., 2007) and Que (Lee et al., 2010).

For Gen, the peak current increased $\sim 1.4$ times [t(14) $=-3.839, p=0.002<0.01]$ and the net charge, $\sim 1.9$ times $[t(14)=-4.151, p<0.001]$ respect to the control (Table 1). No significant differences in the decay time constants were observed in the presence of Gen (Table 1) compared to the corresponding controls in its absence $\left(\tau_{\text {fast }}=53 \pm 21 \mathrm{~ms}\right.$ and $\tau_{\text {slow }}=1062 \pm 739 \mathrm{~ms}$ ) [t(14) $=-0.240, \mathrm{p}=0.814$ for $\tau_{\text {fast }}$ and $\mathrm{t}(14)=1.225, \mathrm{p}=0.241$ for $\left.\tau_{\text {slow }}\right]$.

For Que, the peak current increased $\sim 1.2$ times $[t(10)=-3.602, p=0.005<0.01]$ but the net charge did not show a significant increase respect to the control $[t(10)=0.875, p=0.402]$ (Table 1). The decay time constants in the presence of Que (Table 1) did not show significant differences with the corresponding control values determined in the absence of Que $\left(\tau_{\text {fast }}=47 \pm 10 \mathrm{~ms}\right.$ and $\left.\tau_{\text {slow }}=1235 \pm 694 \mathrm{~ms}\right)[\mathrm{t}(12)=-$ 1.096, $\mathrm{p}=0.294$ for $\tau_{\text {fast }}$ and $\mathrm{t}(12)=1.535, \mathrm{p}=0.151$ for $\left.\tau_{\text {slow] }}\right]$.

For Neo, the peak current $[t(12)=-4.725, p<0.001]$ and the net charge $[t(12)=-$ $3.969, p=0.002<0.01$ ] were statistically significantly increased respect to the control ( $\sim 1.2$ times and $\sim 1.9$ times respectively, Table 1$)$. In contrast, the decay time constants in the presence of $\mathrm{Neo}$ (Table 1) did not show significant differences with respect to those determined in its absence $\left(\tau_{\text {fast }}=42 \pm 7 \mathrm{~ms}\right.$ and $\left.\tau_{\text {slow }}=1037 \pm 653 \mathrm{~ms}\right)[\mathrm{t}(12)=0.880$, $\mathrm{p}=0.396$ for $\tau_{\text {fast }}$ and $\mathrm{t}(12)=-0.135, \mathrm{p}=0.895$ for $\left.\tau_{\text {slow }}\right]$.

Although the increase in the peak currents elicited by $100 \mu \mathrm{M}$ ACh was not statistically different among flavonoids $[F(2)=4.755, p=0.093]$, the trend in the rank order for potentiation was the same as that established by concentration-response curves obtained using Xenopus oocytes: Gen > Que Neo.

Altogether, the results indicate that none of the flavonoids affect the decay rates, but they increase the net charge. Also, in the presence of the flavonoids the ratio of the changes in net charge/peak current is close to 1 (Table 1), as expected for type I PAMs (Andersen et al., 2016; Papke and Papke, 2002).

We also evaluated the ability of flavonoids to reactivate desensitized receptors since this is a property that differentiates type I from type II PAMs (Andersen et al., 2016; Chatzidaki et al., 2015; Collins et al., 2011; Young et al., 2008). Figure 2B shows 
that during continuous application of $\mathrm{ACh}(100 \mu \mathrm{M}) \alpha 7$ remained desensitized. A pulse of extracellular solution (buffer) with no drugs applied to the desensitized receptors did not elicit any significant response $(0.11 \pm 0.07$-fold respect to the control current, $n=5$; $\mathrm{N}=4$, Fig. 2B). In contrast, $1 \mu \mathrm{M}$ PNU-120596 reactivated desensitized receptors as evidenced by a robust current, which is kinetically different from the original AChinduced current due to slower decay rate. Compared to the original responses, reactivated currents by $1 \mu \mathrm{M}$ PNU-120596 showed $10 \pm 8$-fold increase in the maximal amplitude and a profound increase in the net charge (2088 $\pm 1767 \%)(n=4, N=4)$. Type I PAMs lacked the ability to recover desensitized currents or they elicited very small currents. The recovered peak currents were $0.55 \pm 0.16$-fold for $2 \mathrm{mM} \mathrm{5-HI}(n=7, \mathrm{~N}=5)$ and $0.57 \pm 0.13$-fold for $10 \mu \mathrm{M} \mathrm{NS}-1738(\mathrm{n}=6, N=3)$ respect to the original currents (Fig. 2B). For flavonoids, the reactivated currents were $0.40 \pm 0.24$-fold for Gen ( $n=5$, $N=5), 0.34 \pm 0.13$-fold for Que $(n=5, N=5)$ and $0.39 \pm 0.09$-fold for Neo $(n=4, N=4)$ (Fig. 2B).

Thus, we conclude that the three flavonoids cannot produce significant reactivation of desensitized $\alpha 7$ receptors, which is in line with their classification as type I PAMs.

\subsection{Deciphering $\alpha 7$ potentiation by flavonoids at the single-channel level.}

To decipher the allosteric modulation of flavonoids at the molecular level, we performed cell-attached patches in the presence of $100 \mu \mathrm{M}$ ACh and flavonoids $(5 \mu \mathrm{M}$ $100 \mu \mathrm{M})$ (Table 2 and Fig. 3). In the absence of flavonoids, single-channel currents activated by $100 \mu \mathrm{M}$ ACh appeared mainly as brief and isolated openings or as several openings in quick succession, known as bursts (Table 2 and Fig.3). The open time and burst duration histograms were described by the sum of two exponential components (Fig. 3A).

In the presence of Gen, openings elicited by ACh were markedly prolonged and coalesced into long-duration bursts (Fig. 3). Potentiation became evident in the complete range of concentration evaluated, even at a concentration as low as $5 \mu \mathrm{M}$ (Table 2). The open duration histograms in the presence of Gen were described by three exponential components whereas the burst duration histograms were fitted by three exponential components for 5-10 $\mu \mathrm{M}$ Gen and by four exponential components for 25-100 $\mu \mathrm{M}$ Gen (Fig. 3A). The maximal potentiation was reached at $25 \mu \mathrm{M}$. At 25$100 \mu \mathrm{M}$ Gen, the mean open and burst durations were $\sim 6$-fold and $\sim 35$-fold longer than in absence of the flavonoid, respectively (Table 2, Fig $3 \mathrm{~A}$ ). The differences in the 
degree of potentiation among Gen concentrations were determined by the One-Way ANOVA test $\left[F(4)=18.882, p<0.001\right.$ for $\tau_{\text {open }}$ and $F(4)=42.421, p<0.001$ for $\left.\tau_{\text {burst }}\right]$.

For Que, no changes were observed at $5 \mu \mathrm{M}$ and potentiation became evident at $10 \mu \mathrm{M}$, which is in line with the lower potency compared to Gen determined by concentration-response curves. The open and burst duration histograms in presence of Que at potentiating concentrations were fitted by three exponential components (Fig. $3 \mathrm{~A})$. At $10 \mu \mathrm{M}$, the mean open and burst durations increased slightly but the increase was statistically significant. The maximal increase in mean open ( 3 -fold) and burst durations ( 10-fold) was reached at $25 \mu \mathrm{M}$ (Table 2, Fig. 3A). The differences in the degree of potentiation among Que concentrations were determined by the One-Way ANOVA test $\left[F(4)=25.842, p<0.001\right.$ for $\tau_{\text {open }}$ and $F(4)=55.755, p<0.001$ for $\left.\tau_{\text {burst }}\right]$.

For $\mathrm{Neo}$, potentiation became evident at $10 \mu \mathrm{M}$ as an increase in the burst duration but not in the open duration. At 25-50 $\mu \mathrm{M}$, potentiation reached the maximal level with an increase of $\sim 2$-fold and $\sim 8$-fold in the mean open and burst durations, respectively (Table 2, Fig. 3A). The open and burst duration histograms in presence of $\mathrm{Neo}$ at potentiating concentrations were fitted by three exponential components (Fig. 3A). At $100 \mu \mathrm{M} \mathrm{Neo}$, there was a decrease in potentiation that was evidenced as a reduction of the mean burst and open durations. This observation may be explained by additional channel blocking by high Neo concentrations. The differences in the degree of potentiation among Neo concentrations were determined by the One-Way ANOVA test $\left[F(4)=7.848, p=0.001\right.$ for $\tau_{\text {open }}$ and $F(4)=14.686, p=0.005<0.01$ for $\left.\tau_{\text {burst }}\right]$.

In summary, the comparison of the maximal effects among the different flavonoids at $50 \mu \mathrm{M}$ shows that Gen induces the highest increase in open and burst durations and that the apparent efficacy rank order, measured as the increase in open and burst durations, is Gen $>$ Que $\geq$ Neo, similar to the rank order obtained from concentration-response curves in oocytes $\left[F(2)=71.330, p<0.001\right.$ for $\tau_{\text {open }}$ and $F(2)=23.134, p<0.001$ for $\left.\tau_{\text {burst }}\right]$ (Fig. 3B).

We also evaluated if flavonoids affect single-channel amplitude. For $\alpha 7$ in the absence of PAMs, there is a wide range of channel amplitudes because the brief open channel lifetime does not allow full resolution. However, in the presence of PAMs or if only events longer than $0.3 \mathrm{~ms}$ are considered, it is possible to resolve the full amplitude of the channel that is $\sim 10 \mathrm{pA}(10.03 \pm 0.32 \mathrm{pA}, \mathrm{n}=5, \mathrm{~N}=5)$ (Andersen et al., 2013; Nielsen et al., 2018). In the presence of $50 \mu \mathrm{M}$ flavonoid and $100 \mu \mathrm{M}$ ACh, the highest and major amplitudes were $10.19 \pm 0.51 \mathrm{pA}$ for Gen $[\mathrm{t}(8)=-0.612, \mathrm{p}=0.557$, $\mathrm{n}=5, \mathrm{~N}=4], 9.78 \pm 0.31 \mathrm{pA}$ for Que $[\mathrm{t}(7)=1.175, \mathrm{p}=0.278, \mathrm{n}=4, \mathrm{~N}=3]$ and $10.26 \pm 0.23 \mathrm{pA}$ for Neo $[t(7)=-1.251, p=0.251, n=4, N=4]$. Thus, flavonoids do not modify the single- 
channel amplitude. Moreover, flavonoids allow complete resolution of the channel amplitude due to their capability of increasing the mean open and burst durations.

\subsection{Structural determinants of $\alpha 7$ potentiation by flavonoids}

In order to provide further information about how flavonoids allosterically modulate $\alpha 7$, we explored the action of Gen, Que and Neo on the $\alpha 7-5 \mathrm{HT}_{3} \mathrm{~A}$ chimera, which carries human $\alpha 7$ sequence up to the beginning of the TM1 domain and mouse 5- $\mathrm{HT}_{3} \mathrm{~A}$ sequence thereafter (Andersen et al., 2016; Bouzat et al., 2004; Rayes et al., 2005). Whereas Gen and Que were shown to negatively modulate $5-\mathrm{HT}_{3} \mathrm{~A}$ receptors (Goutman et al., 2003; Grønlien et al., 2010; Lee et al., 2008, 2005), both flavonoids exert the opposite effect on $\alpha 7$ receptors. Thus, the use of the chimeric receptor constitutes a good approach to identify the structural determinants of potentiation.

While Gen slightly inhibited the mean open and burst durations, Que and Neo did not affect $\alpha 7-5 \mathrm{HT}_{3} \mathrm{~A}$ channel properties (Table 2, Fig. 4). Thus, none of the three flavonoids $(50 \mu \mathrm{M})$ act as PAMs of $\alpha 7-5 \mathrm{HT}_{3} \mathrm{~A}$ chimeric receptors. These results suggest a prominent role of the $\alpha 7$ TMD or of the ECD-TMD interface to allow potentiation by flavonoids.

Previous studies have shown that simultaneous mutations of five transmembrane residues in $\alpha 7$ receptors inhibit potentiation by type II PAMs, proposing this region as a PAM binding site (DaCosta et al., 2011; Young et al., 2008). However, type I PAMs such as NS-1738 may bind to this transmembrane site as well (Collins et al., 2011). We therefore sought to explore flavonoid actions at the quintuple mutant $\alpha 7$ ( $\alpha 7$ TSLMF).

Neither of the flavonoids $(50 \mu \mathrm{M})$ potentiated $\alpha 7$ TSLMF, even more, Gen decreased significantly the mean open duration (Table 2, Fig. 5). Thus, the five amino acids in the transmembrane domain seem to be essential for flavonoid potentiation.

These results reveal that although the three flavonoids behave as type I PAMs, they share the same structural determinants for potentiation located in the transmembrane domain as the prototype type II PAM, PNU-120596.

\section{5. $\alpha 7$ activation and potentiation by flavonoids decrease ROS intracellular levels}

Given the possibility that $\alpha 7$ potentiation is involved in the neuroprotective role of flavonoids, we evaluated how their antioxidant effects are linked to $\alpha 7$ signalling. 
We measured intracellular ROS levels using DCFDA and tested changes mediated by exposing cells to flavonoids, to the specific $\alpha 7$ agonist PNU-282989 (Bodnar et al., 2005; Hajos et al., 2004) and to the agonist/flavonoid combination for 24 h. For these experiments, the concentration of flavonoids was $50 \mu \mathrm{M}$, at which the maximal potentiation of $\alpha 7$ receptor was achieved, and the concentration of PNU282987 was $10 \mu \mathrm{M}$, as previously used in different in vitro and in vivo systems (Di Cesare Mannelli et al., 2015; Hu et al., 2009; Navarro et al., 2016, 2015; Parada et al., 2013, 2010; Tsoyi et al., 2011; Zanetti et al., 2016). The initial treatment duration was $24 \mathrm{~h}$ in order to ensure the activation of intracellular signalling pathways described for $\alpha 7$ and the tested flavonoids (Boadi et al., 2016; Dajas et al., 2013; Godoy et al., 2017; Parada et al., 2013, 2010; Qian et al., 2015; Tsoyi et al., 2011; Williams et al., 2004). Fluorescence images were taken after 24-h incubation under the different conditions.

The treatments with $50 \mu \mathrm{M}$ flavonoid, $10 \mu \mathrm{M}$ PNU-282987 or their combination decreased the DCF fluorescence observed in cells in each visual field compared to the control group pre-treated with DMSO (Fig. 6A).

In order to accurately quantify ROS levels, we determined the rate of intracellular ROS generation by measuring the slope of DCF fluorescence as a function of time and normalizing it to that of the control condition (Fig. 6B-C) (Koopman et al., 2006;

Sepúlveda et al., 2013). We also incorporated two additional controls: a dye control (probe solution alone) and a positive control $\left(1 \mathrm{mM} \mathrm{H}_{2} \mathrm{O}_{2}\right)$ to verify the correct performance and response capacity of the probe (Bian et al., 2015; Sepúlveda et al., 2013). The linearity of the increase in fluorescence was maintained during the 30-min measurement, and the set of points were fitted by linear regression $\left(r^{2} \sim 0.96-0.99\right.$, Fig. $6 \mathrm{~B})$.

Consistent with the well-known antioxidant capacity of flavonoids, the intracellular ROS production was significantly reduced in cells treated with flavonoids for $24 \mathrm{~h}$ compared to non-treated cells $[\mathrm{t}(8)=7.840, \mathrm{p}<0.001$ for Gen, $\mathrm{t}(8)=12.010, \mathrm{p}<0.001$ for Que and $t(8)=7.016, p<0.001$ for $\mathrm{Neo}, \mathrm{n}=5, \mathrm{~N}=5$ for each condition] (Fig. 6B-C). Under our experimental conditions, there were no differences in ROS levels between Gen, Que and $\mathrm{Neo}[\mathrm{F}(2)=0.381, \mathrm{p}=0.691]$. Interestingly, when $\alpha 7$ was activated by $10 \mu \mathrm{M}$ PNU-282987, ROS levels also decreased respect to the control condition $[\mathrm{t}(20)=7.911$, $\mathrm{p}<0.001, \mathrm{n}=11, \mathrm{~N}=11$, Fig. 6B,C]. Although PNU-282987 is considered a selective $\alpha 7$ agonist, to further verify that it was mediating the effect through $\alpha 7$, we pre-treated the cells with the specific antagonist $\alpha$-Bgt (500 nM) for $2 \mathrm{~h}$ before the addition of $10 \mu \mathrm{M}$ PNU-282987 (Fig. 6A-C). Under this condition, no statistically significant differences were found respect to the control condition $[t(16)=1.614, p=0.126, n=9, N=9$, Fig. 6B- 
C], as also observed by fluorescence microscopy (Fig. 6A). Thus, given that $\alpha$-Bgt blocked the decrease in ROS levels exerted by PNU-282987, we confirmed that the effect is mediated through $\alpha 7$. As an additional control, we also showed that $\alpha$-Bgt alone did not affect ROS production [t(16)=-1.191, $p=0.251, n=9, N=9$, Fig. 6A-C].

In cells treated for $24 \mathrm{~h}$ with $10 \mu \mathrm{M}$ PNU-282987 combined with $50 \mu \mathrm{M}$ flavonoid, the intracellular ROS levels decreased significantly respect to the control $[\mathrm{t}(8)=6.840$, $\mathrm{p}<0.001$ for $\mathrm{PNU}+$ Gen, $\mathrm{t}(8)=8.602, \mathrm{p}<0.001$ for $\mathrm{PNU}+$ Que and $\mathrm{t}(8)=8.431, \mathrm{p}<0.001$ for PNU + Neo, $n=5, N=5$ for each condition, Fig 6]. However, no significant differences were found between the conditions containing flavonoids in the absence or presence of PNU-28298 $[F(6)=1.932, p=0.110]$.

With the aim of dissecting the flavonoid $\alpha 7-P A M$ effect from its potent antioxidant effect independent of $\alpha 7$, which may govern the observed decrease in ROS production at $24 \mathrm{~h}$, we applied two different approaches. In one, we reduced the flavonoid concentration (from $50 \mu \mathrm{M}$ to $10 \mu \mathrm{M}$ ) and in the other we also reduced the time of exposure to the flavonoid (from $24 \mathrm{~h}$ to $12 \mathrm{~h}$ ). We performed this set of experiments only for Gen since this flavonoid is the most effective as an $\alpha 7$ PAM.

Reducing Gen concentration from $50 \mu \mathrm{M}$ to $10 \mu \mathrm{M}$ in the 24 h-treatment showed that Gen was still capable of decreasing ROS production compared to the control condition $[t(12)=18.120, p<0.001 n=3, N=3]$. The decrease exerted by $10 \mu \mathrm{M}$ Gen $(\sim 20 \%)$ was slightly lower compared to that of $50 \mu \mathrm{M}(\sim 50 \%)[\mathrm{t}(6)=2.859$, $\mathrm{p}=0.029<0.05, \mathrm{n}=3, \mathrm{~N}=3]$. Then, we combined $10 \mu \mathrm{M}$ Gen, whose antioxidant action independent of $\alpha 7$ was submaximal at $24 \mathrm{~h}$, with $10 \mu \mathrm{M}$ PNU-282987 and we observed a more pronounced decrease in ROS levels than those exerted by either $10 \mu \mathrm{M}$ Gen $[\mathrm{t}(4)=-5.604, \mathrm{p}=0.005<0.01, \mathrm{n}=3, \mathrm{~N}=3]$ or $10 \mu \mathrm{M}$ PNU-282987 [t(10)=2.883, $\mathrm{p}=0.016<0.05, \mathrm{n}=9, \mathrm{~N}=9$ ). Nevertheless, in the combined treatment the maximal achieved reduction in the ROS generation rate was similar to that obtained in presence of $50 \mu \mathrm{M}$ Gen (alone or with PNU-282987) [ $F(2)=0.472, p=0.637]$. Thus, it seems that under these conditions similar minimal ROS levels can be reached either by the antioxidant activity of Gen independent of $\alpha 7$ or by the combination of its antioxidant activities mediated and not by $\alpha 7$.

To unmask even more the effect of Gen dependent of $\alpha 7$, we reduced the time of exposure from $24 \mathrm{~h}$ to $12 \mathrm{~h}$. With 12-h treatment, the antioxidant activity of Gen was neither detected at $10 \mu \mathrm{M}$ nor at $50 \mu \mathrm{M}$ since ROS generation rate was not different from that of the control condition $[t(12)=-1.716, p=0.112, n=7, N=7$ for $10 \mu \mathrm{M}$ Gen and $\mathrm{t}(12)=-1.145, \mathrm{p}=0.275, \mathrm{n}=7, \mathrm{~N}=7$ for $50 \mu \mathrm{M}$ Gen] (Fig. 6D-E). In contrast, incubation of 
cells for $12 \mathrm{~h}$ with $10 \mu \mathrm{M}$ PNU-282987 reduced ROS production in a statistically significant manner $[\mathrm{t}(12)=-1.145, \mathrm{p}=0.0172<0.05, \mathrm{n}=7, \mathrm{~N}=7]$, although the decrease was lower than in the $24 \mathrm{~h}$ treatment $[\mathrm{t}(16)=2.429, \mathrm{p}=0.0273<0.05$, Fig. $6 \mathrm{C}, \mathrm{E})$. Interestingly, 12-h co-incubation with PNU-282987 and Gen $(10 \mu \mathrm{M}$ or $50 \mu \mathrm{M})$ produced a significant decrease in the ROS levels compared to the control condition $[\mathrm{t}(12)=9.052, \mathrm{p}<0.001, \mathrm{n}=7, \mathrm{~N}=7$ for $\mathrm{PNU}+$ Gen $10 \mu \mathrm{M}$ and $\mathrm{t}(12)=9.849, \mathrm{p}<0.001, \mathrm{n}=7$, $\mathrm{N}=7$ for $\mathrm{PNU}+$ Gen $50 \mu \mathrm{M}]$. The reduction was even more pronounced than that induced by PNU-282987 alone $[t(12)=3.154, p=0.00832<0.01, n=7, N=7$ for PNU + Gen $10 \mu \mathrm{M}$ and t(12)=3.523, $\mathrm{p}=0.00420<0.01, \mathrm{n}=7, \mathrm{~N}=7$ for $\mathrm{PNU}+$ Gen $50 \mu \mathrm{M}$ ], thus demonstrating that the $\alpha 7-P A M$ activity of Gen enhanced cell protection. We confirmed that the Gen effect was mediated through $\alpha 7$ since it was blocked by $\alpha$-Bgt ( $500 \mathrm{nM})$ $[\mathrm{t}(4)=-0.804, \mathrm{p}=0.466, \mathrm{n}=3, \mathrm{~N}=3$ for $\mathrm{PNU}+$ Gen $10 \mu \mathrm{M}+\alpha-$ Bgt and $\mathrm{t}(4)=-0.942$, $\mathrm{p}=0.399, \mathrm{n}=3, \mathrm{~N}=3$ for PNU + Gen $50 \mu \mathrm{M}+\alpha$-Bgt, Fig. 6E). The effects determined by the kinetic assays were in line with those determined by fluorescence microscopy (Fig. 6D).

Overall, this set of experiments revealed that the effects of Gen on ROS production take place earlier through its activity as an $\alpha 7$ PAM than through its activity mediated by $\alpha 7$-independent mechanisms. 


\section{DISCUSSION}

Despite their common neurological and neuroprotective effects, the interactions between flavonoids and $\alpha 7$ have been poorly explored. Here, by using a single-channel approach we have elucidated, for the first time, the molecular mechanisms of the flavonoid-induced potentiation of $\alpha 7$ receptors. Previous studies have shown that flavonoids such as Gen (Grønlien et al., 2010, 2007) and Que (Lee et al., 2010) potentiate $\alpha 7$ macroscopic currents through a type I PAM mechanism. We confirmed these observations and identified a neoflavonoid as a novel $\alpha 7$ PAM. Our findings clearly demonstrate that the type I PAM actions of all flavonoids tested increase the open channel lifetime and induce activation in bursts, thus modulating $\alpha 7$ kinetics.

We studied three different classes of flavonoids differing in the position of the Bring in the benzopyrone moiety. Que is a flavonol that constitutes the major component of flavonoids dietary intake and exhibits the most prominent antioxidant and antiinflammatory activity (Bakhtiari et al., 2017; Spencer et al., 2012). Gen is an isoflavone abundant in soy, which improves short and long term memory, supresses inflammatory pathways and oxidative stress, and may be involved in some estrogenic-receptor signalling pathways (Bakhtiari et al., 2017; Ganai and Farooqi, 2015; Spencer et al., 2012). The compound 5,7-dihydroxy-4-phenylcoumarin (Ulubelen et al., 1982) is a neoflavonoid, which is the less explored class of flavonoids. The unique structure and popularity of neoflavonoids in traditional medicine have made them attractive pharmacological compounds. In this regard, the tested Neo is an inhibitor of CAMP phosphodiesterase (Kusano et al., 1991), and an antioxidant (Veselinović et al., 2014), anti-bacterial (Veselinović et al., 2015) and anti-melanogenic agent (Veselinović et al., 2017).

\subsection{Pharmacological characterization of flavonoids at the macroscopic and single-channel level}

Flavonoids enhance agonist-induced peak currents without significantly affecting current decay rates and do not reactivate desensitized receptors. At the single-channel level, they increase the open-channel lifetime and induce activation in bursts, which are composed by several openings in quick succession, indicating that they do affect $\alpha 7$ kinetics as described for other type I PAMs (Andersen et al., 2016). The comparison of flavonoid potencies by the $\mathrm{EC}_{50}$ values determined from macroscopic recordings shows that Gen and Neo are more potent than Que. Regarding efficacy, Gen is the most efficacious $\alpha 7$ PAM, as based on the increase of the maximal current and open and burst durations. Gen, Que and Neo increase $\sim 6, \sim 3$ 
and $\sim 2$ times, respectively, the mean open duration and $\sim 35, \sim 10$ and $\sim 8$ times, respectively, the mean burst duration. However, the changes at the macroscopic level are less pronounced. A similar lack of correlation has been reported for NS-1738 (Andersen et al., 2016). Thus, it appears that the burst duration is the most sensitive parameter to quantify the potentiating effects, which, in turn, highlights the importance of analysing single-channel kinetics for a better understanding of the mechanistic changes (Nielsen et al., 2018). In this context, and based on the increase of the burst duration, the rank order for $\alpha 7$ potentiation among several type I PAMs is NS-1378 $\geq$ Gen $\geq 5-\mathrm{HI}>$ Que $\geq$ Neo.

In our study, the maximal level of potentiation was achieved by simultaneous application with the agonist, in contrast to an earlier study which needed preincubation with the flavonoid (Lee et al., 2010). This difference may be due to the differences in the solution exchange rate of the perfusion system employed for recording in Xenopus oocytes. Although Que and Gen are tyrosine kinase inhibitors (Akiyama et al., 1987; Glossmann et al., 1981) and changes in $\alpha 7$ phosphorylation may affect its function and/or cell expression (Charpantier et al., 2005; Cho et al., 2005), the rapid modulatory effects by flavonoids on $\alpha 7$ and on other pLGICs have been shown to be independent of tyrosine kinases (Grønlien et al., 2007; Huang et al., 1999; Huang and Dillon, 2000; Lee et al., 2010). In our hands, the fact that co-application of flavonoids with ACh rapidly affects $\alpha 7$ function in a reversible manner and that a receptor carrying mutations at a PAM binding site, not involving phosphorylation sites, is insensitive to flavonoid potentiation, supports a direct allosteric effect.

Our results also show that the position of the B-ring in the benzopyrone moiety does not change the main mechanism by which flavonoids act in $\alpha 7$. However, it may be involved, together with different hydroxylation patterns, in the slight differences in efficacy and potency observed among flavonoids. Moreover, all tested flavonoids carry hydroxyl substitutions in positions 5 and 7 in the A-ring that were identified as necessary to afford neuronal protection (Dajas et al., 2013; Echeverry et al., 2010).

\subsection{Structural determinants of flavonoid PAM activity}

The binding site(s) for $\alpha 7$ PAMs have not been unequivocally identified from crystal structures of $\alpha 7$ in complex with PAMs. Several PAMs, including type II PAMs (PNU-120596 and TQS) and type I PAMs (ivermectin and LY-2087101) have been proposed to bind to transmembrane site(s) (Collins and Millar, 2010; Young et al., 2008), which may be shared by allosteric modulators displaying very distinct pharmacological effects (Gill-Thind et al., 2015; Gill et al., 2013; Pałczynska et al., 
2012). However, other binding sites in the ECD and/or the ECD-TMD interface have been proposed for type I PAMs (Bertrand et al., 2008; Grønlien et al., 2007;

Targowska-Duda et al., 2018). The $\alpha 7-5 \mathrm{HT}_{3} \mathrm{~A}$ receptor has been extensively used as a model of $\alpha 7$ ECD as well as to dissect the main domains involved in drug modulation. In accordance to previous observations, we found that this chimeric receptor is not potentiated by flavonoids, although it is sensitive to other type I-PAMs, such as $5-\mathrm{HI}$ (Andersen et al., 2016; Grønlien et al., 2010; Williams et al., 2011).

The lack of flavonoid potentiation in $\alpha 7-5 \mathrm{HT}_{3} \mathrm{~A}$ indicates that other domains than the ECD are required for potentiation. Further dissection of the amino acids involved was obtained from the quintuple mutant $\alpha 7$ TSLMF, which is not potentiated by the three classes of flavonoids, indicating the involvement of the transmembrane cavity in flavonoid modulation. This receptor also shows significantly reduced potentiation by type II PAMs (PNU-120596 and PAM-2) and by the type I PAM NS-1738, but full potentiation by 5-HI (Andersen et al., 2016; DaCosta et al., 2011).

It is important to note that Gen not only does not potentiate the chimeric and mutant receptors, but it also reduces the open and burst durations, suggesting that it acts as an allosteric negative modulator (NAM) of both $\alpha 7-5 \mathrm{HT}_{3} \mathrm{~A}$ and the mutant $\alpha 7$ TSLMF. This result agrees with reports showing that PAMs can turn into negative modulators in mutant receptors. For example, mutations in the transmembrane region (S223M, M254L and S277V) convert ivermectin from PAM into a NAM (Collins and Millar, 2010). In agreement, $\alpha 7$ TSLMF receptor contains two of these mutations (S223M and M254L) and is inhibited by Gen.

The fact that Que and Neo neither potentiate nor inhibit the chimeric and mutant receptors while Gen inhibits them may rely on different interactions due to their slight differences in chemical structures. Our work opens doors for further work deciphering the basis underlying the inhibitory effect of Gen.

We demonstrated that flavonoids exhibit a macroscopic type I PAM profile, induce changes in single-channel properties similar to some type I PAMs (Andersen et al., 2016), and require structural determinants of the transmembrane domain as type II PAMs and some type I PAMs (NS-1738 and ivermectin). Thus, our work provides additional information regarding $\alpha 7$ modulation and confirms that the prototypical type I (5-HI) and type II (PNU-120596) PAMs may show the extreme behaviors of a wide range of allosteric modulators. The classification of type I and type II appears to be an oversimplification resulting mainly from macroscopic observations, which highlights the importance of characterizing the molecular mechanisms at single-channel level. 


\subsection{Antioxidant activity of flavonoids through $\alpha 7-P A M$ activity}

We determined the interrelation between $\alpha 7$ modulation and flavonoids in ROS levels, which are involved in aging and neurodegeneration (Schieber and Chandel, 2014). Activation of $\alpha 7$ by a selective agonist (PNU-282987) decreases the ROS generation rate, in line with reports describing antioxidant and anti-inflamatory effects of $\alpha 7$ on different cellular systems (Parada et al., 2013, 2010; Tsoyi et al., 2011). In 24 h-treatment, co-application of flavonoids with the agonist reduces the intracellular ROS production but to an extent similar to that achieved by flavonoids alone at the maximal concentrations. This observation may be explained by a common mechanism for antioxidation mediated by flavonoids and $\alpha 7$-activation which has reached its maximal level in our system and/or by the predominance of the flavonoid antioxidant capacity independent of $\alpha 7$ at this prolonged time of treatment, thus obscuring the antioxidant effect triggered by $\alpha 7$ activation.

The reduction of Gen exposure to $12 \mathrm{~h}$ allowed us to separate the antioxidant effects of Gen independent of $\alpha 7$ from those dependent of $\alpha 7$. Although the antioxidant activity of Gen alone is not detected at $12 \mathrm{~h}$, the flavonoid potentiates the reduction in ROS levels mediated by $\alpha 7$ activation, indicating that its action as type I PAM also constitutes a mechanism of antioxidation. These results also revealed the importance of $\alpha 7$ potentiation by flavonoids as an additional mechanism underlying their neuroprotective role because the effects from their allosteric modulatory action occur at an earlier stage than those related to their solely antioxidant action independent of $\alpha 7$.

It is important to note that the antioxidant effect mediated by $\alpha 7$ activation takes place only in transfected cells, while the flavonoid antioxidant effects independent of $\alpha 7$, occur in all cells. Thus, the difference between both conditions may be underestimated and therefore, the contribution of $\alpha 7$ signalling could be even higher than here determined. Nevertheless, the significant reduction in ROS generation levels in cells treated with the $\alpha 7$ selective agonist alone supports our model for measuring the effects mediated by nAChR activation.

The dual ionotropic/metabotropic activity of $\alpha 7$ is responsible for its role in neuroprotection. Mainly, the neuroprotective effects depend on NF-кB inhibition, which has an antiinflammatory action, and on the pathway Jak2/PI3K/Akt leading to activation of Nrf-2, a transcription factor primarily responsible for cellular defense against oxidative stress (Parada et al., 2013; Tsoyi et al., 2011). Flavonoids also downregulate NF-kB pathways and modulate several signalling cascades, including PI3K/Akt that leads to upregulation of Nrf-2 (Dajas et al., 2013; Williams et al., 2004). It is possible 
that $\alpha 7$ through both its ionotropic and metabotropic responses triggers more rapidly these common pathways than flavonoids alone. In the presence of flavonoids, the more sustained activation of $\alpha 7$ leading to higher calcium-influx potentiates the $\alpha 7$-triggered intracellular pathways that mediate antioxidation. Thus, positive modulation on $\alpha 7$ may represent a spare mechanism by which flavonoids exert their antioxidant activity and, therefore, their neuroprotective role.

\subsection{Therapeutic impact of flavonoids acting as $\alpha 7$ PAMs}

Previous studies have explored the selectivity of flavonoids on different LGICs, showing a positive effect only on $\alpha 7$ and an inhibitory effect on most neurotransmitter receptors, including GABA-, serotonin-, ACh-, glycine- and glutamate-activated receptors (Goutman et al., 2003; Grønlien et al., 2007; Huang et al., 1999; Huang and Dillon, 2000; Lee et al., 2011a, 2011c, 2011b, 2008, 2007, 2005; Shin et al., 2010). This strict selectivity for potentiation may result in a promising feature for therapy. Furthermore, modifications of flavonoid structure have allowed different pharmacological effects on GABA receptors (Hanrahan et al., 2011; Wasowski and Marder, 2012). This demonstrates that not only the natural flavonoids, but also the synthetic ones, exhibit a high potential for therapeutic development.

The advantages of PAMs over agonists for therapy are the maintainance of the temporal and spatial pattern of the endogenous neurotransmitter, higher selectivity for binding into allosteric sites, reduction of tolerance due to $\alpha 7$ desensitization and neuroprotective action (Bertrand and Gopalakrishnan, 2007; Bouzat et al., 2018; Chatzidaki and Millar, 2015; Faghih et al., 2008; Uteshev, 2014; Williams et al., 2011). Nevertheless, there is a controversy about the possible cytotoxicity of PAMs due to the high increase in intracellular calcium levels ( $\mathrm{Ng}$ et al., 2007; Liu et al., 2009; Williams et al., 2012; Guerra-Álvarez et al., 2015; Uteshev, 2016). Type II PAMs are the most controversial due to their ability to potentiate $\alpha 7$ currents with high efficacy, decrease desensitization and reactivate desensitized receptors (Guerra-Álvarez et al., 2015; Hu et al., 2009; Ng et al., 2007; Uteshev, 2016; Williams et al., 2012). Type I PAMs may be less cytotoxic than type II PAMs because potentiation is lower and receptor desensitization still occurs, which acts as a filter against excessive stimulation (GuerraÁlvarez et al., 2015; Hu et al., 2009; Ng et al., 2007; Williams et al., 2012). Therefore, the use of flavonoids is a promising therapeutic strategy for enhancing $\alpha 7$ function, because they do not change the desensitization rate and do not reactivate desensitized receptors. 
As natural compounds with a broad spectrum of beneficial pharmacological and biological activities, including their role as $\alpha 7$ PAMs reported here, flavonoids are suitable candidates for the treatment of multifactorial diseases. We here evaluated the action of unmetabolized flavonoids but it has been shown for several compounds that the conjugated and derivatives forms of polyphenols have similar or greater bioactivity interacting with the same signalling pathways (Kawai, 2018; Unno et al., 2017).

The intake of flavonoids in the diet ranges from 60 to $350 \mathrm{mg} /$ day (Johnston, 2015), reaching high nanomolar-low micromolar concentration levels in in vivo studies, which are correlated with those showing effects in vitro (Krasieva et al., 2015; Schaffer and Halliwell, 2012). Interestingly, some polyphenols are concentrated in neural tissue, and therefore the achieved concentration may be higher (Kalt et al., 2008; Milbury and Kalt, 2010). The effects of flavonoids as $\alpha 7$ PAMs occur at the low micromolar range and, therefore, at clinically achievable concentrations. Furthermore, the beneficial actions of these natural compounds may be due to a synergic effect of the multiplicity of flavonoids ingested in the diet.

\section{CONCLUSIONS}

The $\alpha 7$ nicotinic receptor participates in cognition, neuroprotection and inflammation and its potentiation is emerging as promising therapeutic strategy for neurological and inflammatory disorders. On the other hand, flavonoids are plant polyphenolic compounds showing neuroprotective, anti-inflammatory and pro-cognitive actions. Besides their wellknown antioxidant activity, flavonoids trigger intracellular pathways and interact with receptors, including $\alpha 7$. We here identified a neoflavonoid as a novel $\alpha 7$ PAM and deciphered the molecular mechanisms underlying the PAM actions of three classes of flavonoids. They potentiate macroscopic responses without affecting receptor desensitization, increase open-channel lifetime and induce channel activation in episodes of successive openings, thus modulating $\alpha 7$ kinetics. Flavonoids share transmembrane structural determinants with other non-structurally related PAMs. Besides the well-described antioxidant actions of flavonoids, the enhancement of $\alpha 7$ activation has also a functional role reducing the ROS generation rate in human cells. Thus, allosterically potentiation of $\alpha 7$ is proposed as an additional mechanism underlying the neuroprotective actions of flavonoids, which, in turn, may be used as scaffolds for designing new therapeutic agents. The identification of novel candidate PAMs as well as the understanding of their actions at the molecular level are required for the still ongoing development of these promising therapeutic compounds. 


\section{ACKNOWLEDGMENTS}

This work was supported by grants from Universidad Nacional del Sur [PGI 24/B227] and Agencia Nacional de Promoción Científica y Tecnológica [PICT-2015 0941, PICT2017 1170] to C.B.; a grant from Oxford Brookes University to I.B.; and a grant from Company of Biologists [JCSTF-180207] to B.E.N. 


\section{REFERENCES}

Akiyama, T., Ishida, J., Nakagawa, S., Ogawara, H., Watanabe, S., Itoh, N., Shibuya, M., Fukami, Y., 1987. Genistein, a specific inhibitor of tyrosine-specific protein kinases. J. Biol. Chem. 262, 5592-5595.

Andersen, N., Corradi, J., Sine, S.M., Bouzat, C., 2013. Stoichiometry for activation of neuronal $\alpha 7$ nicotinic receptors. Proc. Natl. Acad. Sci. U. S. A. 110, 20819-20824. https://doi.org/10.1073/pnas.1315775110

Andersen, N., Nielsen, B.E., Corradi, J., Tolosa, M.F., Feuerbach, D., Arias, H.R., Bouzat, C., 2016. Exploring the Positive Allosteric Modulation of Human $\alpha 7$ Nicotinic Receptors from a Single-Channel Perspective. Neuropharmacology 107, 189-200. https://doi.org/10.1016/j.neuropharm.2016.02.032

Bakhtiari, M., Panahi, Y., Ameli, J., Darvishi, B., 2017. Protective effects of flavonoids against Alzheimer's disease-related neural dysfunctions. Biomed. Pharmacother. 93, 218-229. https://doi.org/10.1016/j.biopha.2017.06.010

Bakoyiannis, I., Daskalopoulou, A., Pergialiotis, V., Perrea, D., 2019. Phytochemicals and cognitive health: Are flavonoids doing the trick? Biomed. Pharmacother. 109, 1488-1497. https://doi.org/10.1016/j.biopha.2018.10.086

Bertrand, D., Bertrand, S., Cassar, S., Gubbins, E., Li, J., Gopalakrishnan, M., 2008. Positive Allosteric Modulation of the a7 Nicotinic Acetylcholine Receptor: Ligand Interactions with Distinct Binding Sites and Evidence for a Prominent Role of the M2-M3 Segment. Mol. Pharmacol. 74, 1407-1416. https://doi.org/10.1124/mol.107.042820

Bertrand, D., Gopalakrishnan, M., 2007. Allosteric modulation of nicotinic acetylcholine receptors. Biochem. Pharmacol. 74, 1155-1163. https://doi.org/10.1016/j.bcp.2007.07.011

Bian, Y.Y., Guo, J., Majeed, H., Zhu, K.X., Guo, X.N., Peng, W., Zhou, H.M., 2015. Ferulic acid renders protection to HEK293 cells against oxidative damage and apoptosis induced by hydrogen peroxide. Vitr. Cell. Dev. Biol. - Anim. 51, 722729. https://doi.org/10.1007/s11626-015-9876-0

Boadi, W.Y., Amartey, P.K., Lo, A., 2016. Effect of quercetin, genistein and kaempferol on glutathione and glutathione-redox cycle enzymes in 3T3-L1 preadipocytes.

Drug Chem. Toxicol. 39, 239-247.

https://doi.org/10.3109/01480545.2015.1082135

Bodnar, A.L., Cortes-Burgos, L.A., Cook, K.K., Dinh, D.M., Groppi, V.E., Hajos, M., Higdon, N.R., Hoffmann, W.E., Hurst, R.S., Myers, J.K., Rogers, B.N., Wall, T.M., Wolfe, M.L., Wong, E., 2005. Discovery and structure-activity relationship of quinuclidine benzamides as agonists of $\alpha 7$ nicotinic acetylcholine receptors. J. Med. Chem. 48, 905-908. https://doi.org/10.1021/jm049363q

Bouzat, C., Bartos, M., Corradi, J., Sine, S.M., 2008. The interface between extracellular and transmembrane domains of homomeric Cys-loop receptors governs open-channel lifetime and rate of desensitization. J. Neurosci. 28, 78087819. https://doi.org/10.1523/JNEUROSCI.0448-08.2008

Bouzat, C., Bren, N., Sine, S.M., 1994. Structural basis of the different gating kinetics of fetal and adult acetylcholine receptors. Neuron 13, 1395-1402. https://doi.org/10.1016/0896-6273(94)90424-3

Bouzat, C., Gumilar, F., Spitzmaul, G., Wang, H., Rayes, D., Hansen, S.B., Taylor, P., Sine, S.M., 2004. Coupling of agonist binding to channel gating in an ACh-binding 
protein linked to an ion channel. Nature 430, 896-900.

https://doi.org/10.1038/nature02753

Bouzat, C., Lasala, M., Nielsen, B.E., Corradi, J., Esandi, M. del C., 2018. Molecular function of $\alpha 7$ nicotinic receptors as drug targets. J. Physiol. 596, 1847-1861. https://doi.org/10.1113/JP275101

Buckingham, S.D., Jones, A.K., Brown, L.A., Sattelle, D.B., 2009. Nicotinic Acetylcholine Receptor Signalling: Roles in Alzheimer's Disease and Amyloid Neuroprotection. Pharmacol. Rev. 61, 39-61. https://doi.org/10.1124/pr.108.000562

Carbone, A.L., Moroni, M., Groot-Kormelink, P.J., Bermudez, I., 2009. Pentameric concatenated ( $\alpha 4) 2(\beta 2) 3$ and $(\alpha 4) 3(\beta 2) 2$ nicotinic acetylcholine receptors: subunit arrangement determines functional expression. Br. J. Pharmacol. 156, 970-981. https://doi.org/10.1111/j.1476-5381.2008.00104.x

Changeux, J.P., Taly, A., 2008. Nicotinic receptors, allosteric proteins and medicine. Trends Mol. Med. 14, 93-102. https://doi.org/10.1016/j.molmed.2008.01.001

Charpantier, E., Wiesner, A., Huh, K.-H., Ogier, R., Hoda, J.-C., Allaman, G., Raggenbass, M., Feuerbach, D., Bertrand, D., Fuhrer, C., 2005. Alpha7 neuronal nicotinic acetylcholine receptors are negatively regulated by tyrosine phosphorylation and Src-family kinases. J. Neurosci. 25, 9836-49. https://doi.org/10.1523/JNEUROSCI.3497-05.2005

Chatzidaki, A., Millar, N.S., 2015. Allosteric modulation of nicotinic acetylcholine receptors. Biochem. Pharmacol. 97, 408-417. https://doi.org/10.1016/j.bcp.2015.07.028

Chatzidaki, A., Oyley, J.M.D., Gill-thind, J.K., Sheppard, T.D., Millar, N.S., D'Oyley, J.M., Gill-thind, J.K., Sheppard, T.D., Millar, N.S., 2015. The influence of allosteric modulators and transmembrane mutations on desensitisation and activation of $\alpha 7$ nicotinic acetylcholine receptors. Neuropharmacology 97, 75-85. https://doi.org/10.1016/j.neuropharm.2015.05.006

Cho, C., Song, W., Leitzell, K., Teo, E., Meleth, A.D., Quick, M.W., Lester, R.A.J., 2005. Rapid upregulation of alpha7 nicotinic acetylcholine receptors by tyrosine dephosphorylation. J. Neurosci. 25, 3712-23. https://doi.org/10.1523/JNEUROSCI.5389-03.2005

Collins, T., Millar, N.S., 2010. Nicotinic Acetylcholine Receptor Transmembrane Mutations Convert Ivermectin from a Positive to a Negative Allosteric Modulator. Mol. Pharmacol. 78, 198-204. https://doi.org/10.1124/mol.110.064295

Collins, T., Young, G.T., Millar, N.S., 2011. Competitive binding at a nicotinic receptor transmembrane site of two $\alpha 7$-selective positive allosteric modulators with differing effects on agonist-evoked desensitization. Neuropharmacology 61, 1306-1313. https://doi.org/10.1016/j.neuropharm.2011.07.035

Corcoran, M.P., McKay, D.L., Blumberg, J.B., 2012. Flavonoid Basics: Chemistry, Sources, Mechanisms of Action, and Safety. J. Nutr. Gerontol. Geriatr. 31, 176189. https://doi.org/10.1080/21551197.2012.698219

Corradi, J., Bouzat, C., 2016. Understanding the Bases of Function and Modulation of a7 Nicotinic Receptors: Implications for Drug Discovery. Mol. Pharmacol. 90, 288299. https://doi.org/10.1124/mol.116.104240

Corradi, J., Gumilar, F., Bouzat, C., 2009. Single-channel kinetic analysis for activation and desensitization of homomeric 5-HT3A receptors. Biophys. J. 97, 1335-1345. 
https://doi.org/10.1016/j.bpj.2009.06.018

DaCosta, C.J.B., Free, C.R., Corradi, J., Bouzat, C., Sine, S.M., 2011. Single-Channel and Structural Foundations of Neuronal $\alpha 7$ Acetylcholine Receptor Potentiation. J. Neurosci. 31, 13870-13879. https://doi.org/10.1523/JNEUROSCI.2652-11.2011

DaCosta, C.J.B., Free, C.R., Sine, S.M., 2015. Stoichiometry for $\alpha$-bungarotoxin block of $\alpha 7$ acetylcholine receptors. Nat. Commun. 6, 8057-8067. https://doi.org/10.1038/ncomms9057

Dajas-Bailador, F., Wonnacott, S., 2004. Nicotinic acetylcholine receptors and the regulation of neuronal signalling. Trends Pharmacol. Sci. 25, 317-324. https://doi.org/10.1016/j.tips.2004.04.006

Dajas, F., Abin-Carriquiry, J.A., Arredondo, F., Echeverry, C., Felicia, R.-M., 2013. Neuroprotective Actions of Flavones and Flavonols: Mechanisms and Relationship to Flavonoid Structural Features. Cent. Nerv. Syst. Agents Med. Chem. 13, 30-35. https://doi.org/10.2174/1871524911313010005

Di Cesare Mannelli, L., Tenci, B., Zanardelli, M., Failli, P., Ghelardini, C., 2015. $\alpha 7$ Nicotinic Receptor Promotes the Neuroprotective Functions of Astrocytes against Oxaliplatin Neurotoxicity. Neural Plast. 2015, 396908. https://doi.org/10.1155/2015/396908

Dineley, K.T., Pandya, A.A., Yakel, J.L., 2015. Nicotinic ACh receptors as therapeutic targets in CNS disorders. Trends Pharmacol. Sci. 36, 96-108. https://doi.org/10.1016/j.tips.2014.12.002

Ebrahimi, A., Schluesener, H., 2012. Natural polyphenols against neurodegenerative disorders: Potentials and pitfalls. Ageing Res. Rev. 11, 329-345. https://doi.org/10.1016/j.arr.2012.01.006

Echeverry, C., Arredondo, F., Abin-Carriquiry, J.A., Midiwo, J.O., Ochieng, C., Kerubo, L., Dajas, F., 2010. Pretreatment with Natural Flavones and Neuronal Cell Survival after Oxidative Stress: A Structure-Activity Relationship Study. J. Agric. Food Chem. 58, 2111-2115. https://doi.org/10.1021/jf902951v

Egea, J., Buendia, I., Parada, E., Navarro, E., León, R., Lopez, M.G., 2015. Antiinflammatory role of microglial alpha7 $\mathrm{nAChRs}$ and its role in neuroprotection. Biochem. Pharmacol. 97, 463-472. https://doi.org/10.1016/j.bcp.2015.07.032

Faghih, R., Gopalakrishnan, M., Briggs, C.A., 2008. Allosteric modulators of the $\alpha 7$ nicotinic acetylcholine receptor. J. Med. Chem. 51, 701-712. https://doi.org/10.1021/jm070256g

Flanagan, E., Müller, M., Hornberger, M., Vauzour, D., 2018. Impact of Flavonoids on Cellular and Molecular Mechanisms Underlying Age-Related Cognitive Decline and Neurodegeneration. Curr. Nutr. Rep. 7, 49-57. https://doi.org/10.1007/s13668-018-0226-1

Ganai, A.A., Farooqi, H., 2015. Bioactivity of genistein: A review of in vitro and in vivo studies. Biomed. Pharmacother. 76, 30-38. https://doi.org/10.1016/j.biopha.2015.10.026

Gildawie, K.R., Galli, R.L., Shukitt-Hale, B., Carey, A.N., 2018. Protective Effects of Foods Containing Flavonoids on Age-Related Cognitive Decline. Curr. Nutr. Rep. 7, 39-48. https://doi.org/10.1007/s13668-018-0227-0

Gill-Thind, J.K., Dhankher, P., D’Oyley, J.M., Sheppard, T.D., Millar, N.S., 2015. Structurally Similar Allosteric Modulators of a7 Nicotinic Acetylcholine Receptors 
Exhibit Five Distinct Pharmacological Effects. J. Biol. Chem. 290, 3552-3562. https://doi.org/10.1074/jbc.M114.619221

Gill, J.K., Chatzidaki, A., Ursu, D., Sher, E., Millar, N.S., 2013. Contrasting Properties of $\alpha 7-S e l e c t i v e$ Orthosteric and Allosteric Agonists Examined on Native Nicotinic Acetylcholine Receptors. PLoS One 8, e55047. https://doi.org/10.1371/journal.pone.0055047

Glossmann, H., Presek, P., Eigenbrodt, E., 1981. Quercetin inhibits tyrosine phosphorylation by the cyclic nucleotide-independent, transforming protein kinase, pp60src. Naunyn. Schmiedebergs. Arch. Pharmacol. 317, 100-102. https://doi.org/10.1007/BF00506266

Godoy, J.A., Lindsay, C.B., Quintanilla, R.A., Carvajal, F.J., Cerpa, W., Inestrosa, N.C., 2017. Quercetin Exerts Differential Neuroprotective Effects Against $\mathrm{H} 2 \mathrm{O} 2$ and $A \beta$ Aggregates in Hippocampal Neurons: the Role of Mitochondria. Mol. Neurobiol. 54, 7116-7128. https://doi.org/10.1007/s12035-016-0203-x

Goutman, J.D., Waxemberg, M.D., Doñate-Oliver, F., Pomata, P.E., Calvo, D.J., 2003. Flavonoid modulation of ionic currents mediated by GABA A and GABA C receptors. Eur. J. Pharmacol. 461, 79-87. https://doi.org/10.1016/S00142999(03)01309-8

Grønlien, J.H., Håkerud, M., Ween, H., Thorin-Hagene, K., Briggs, C. a, Gopalakrishnan, M., Malysz, J., 2007. Distinct profiles of alpha7 nAChR positive allosteric modulation revealed by structurally diverse chemotypes. Mol. Pharmacol. 72, 715-24. https://doi.org/10.1124/mol.107.035410

Grønlien, J.H., Ween, H., Thorin-Hagene, K., Cassar, S., Li, J., Briggs, C.A., Gopalakrishnan, M., Malysz, J., 2010. Importance of M2-M3 loop in governing properties of genistein at the $\alpha 7$ nicotinic acetylcholine receptor inferred from $\alpha 7 / 5$ HT3A chimera. Eur. J. Pharmacol. 647, 37-47.

https://doi.org/10.1016/j.ejphar.2010.08.027

Gu, S., Matta, J.A., Lord, B., Harrington, A.W., Sutton, S.W., Davini, W.B., Bredt, D.S., 2016. Brain a7 Nicotinic Acetylcholine Receptor Assembly Requires NACHO. Neuron 89, 948-955. https://doi.org/10.1016/j.neuron.2016.01.018

Guan, Y.Z., Jin, X.D., Guan, L.X., Yan, H.C., Wang, P., Gong, Z., Li, S.J., Cao, X., Xing, Y.L., Gao, T.M., 2015. Nicotine Inhibits Microglial Proliferation and Is Neuroprotective in Global Ischemia Rats. Mol. Neurobiol. 51, 1480-1488. https://doi.org/10.1007/s12035-014-8825-3

Guan, Z.Z., Zhang, X., Ravid, R., Nordberg, A., 2000. Decreased protein levels of nicotinic receptor subunits in the hippocampus and temporal cortex of patients with Alzheimer's disease. J. Neurochem. 74, 237-243. https://doi.org/10.1046/j.1471-4159.2000.0740237.x

Guerra-Álvarez, M., Moreno-Ortega, A.J., Navarro, E., Fernández-Morales, J.C., Egea, J., López, M.G., Cano-Abad, M.F., 2015. Positive allosteric modulation of alpha-7 nicotinic receptors promotes cell death by inducing $\mathrm{Ca} 2+$ release from the endoplasmic reticulum. J. Neurochem. 133, 309-319. https://doi.org/10.1111/jnc.13049

Hajos, M., Hurst, R.S., Hoffmann, W., Krause, M., Wall, T.M., Higdon, N.R., Groppi, V.E., 2004. The Selective a7 Nicotinic Acetylcholine Receptor Agonist PNU282987 [N-[(3R)-1-Azabicyclo[2.2.2]oct-3-yl]-4-chlorobenzamide Hydrochloride] Enhances GABAergic Synaptic Activity in Brain Slices and Restores Auditory Gating Deficits in Anesthetized Rats. J. Pharmacol. Exp. Ther. 312, 1213-1222. 
https://doi.org/10.1124/jpet.104.076968

Hanrahan, J.R., Chebib, M., Johnston, G.A.R., 2011. Flavonoid modulation of GABA A receptors. Br. J. Pharmacol. 163, 234-245. https://doi.org/10.1111/j.14765381.2011.01228.x

Heim, K.E., Tagliaferro, A.R., Bobilya, D.J., 2002. Flavonoid antioxidants : chemistry , metabolism and structure-activity relationships. J. Nutr. Biochem. 13, 572-584. https://doi.org/10.1016/S0955-2863(02)00208-5

Hu, M., Gopalakrishnan, M., Li, J., 2009. Positive allosteric modulation of $\alpha 7$ neuronal nicotinic acetylcholine receptors: Lack of cytotoxicity in PC12 cells and rat primary cortical neurons. Br. J. Pharmacol. 158, 1857-1864. https://doi.org/10.1111/j.1476-5381.2009.00474.x

Huang, R.Q., Dillon, G.H., 2000. Direct inhibition of glycine receptors by genistein, a tyrosine kinase inhibitor. Neuropharmacology 39, 2195-2204.

https://doi.org/10.1016/S0028-3908(00)00046-0

Huang, R.Q., Fang, M.J., Dillon, G.H., 1999. The tyrosine kinase inhibitor genistein directly inhibits GABA(A) receptors. Mol. Brain Res. 67, 177-183.

https://doi.org/10.1016/S0169-328X(99)00061-3

Hurst, R.S., Hajos, M., Raggenbass, M., Wall, T.M., Higdon, N.R., Lawson, J.A., Rutherford-Root, K.L., Berkenpas, M.B., Hoffmann, W.E., Piotrowski, D.W., Groppi, V.E., Allaman, G., Ogier, R., Bertrand, S., Bertrand, D., Arneric, S.P., 2005. A Novel Positive Allosteric Modulator of the a7 Neuronal Nicotinic Acetylcholine Receptor: In Vitro and In Vivo Characterization. J. Neurosci. 25, 4396-4405. https://doi.org/10.1523/JNEUROSCI.5269-04.2005

Johnston, G.A.R., 2015. Flavonoid nutraceuticals and ionotropic receptors for the inhibitory neurotransmitter GABA. Neurochem. Int. 89, 120-125. https://doi.org/10.1016/j.neuint.2015.07.013

Kabbani, N., Nichols, R.A., 2018. Beyond the Channel: Metabotropic Signaling by Nicotinic Receptors. Trends Pharmacol. Sci. 39, 354-366.

https://doi.org/10.1016/j.tips.2018.01.002

Kadir, A., Almkvist, O., Wall, A., Långström, B., Nordberg, A., 2006. PET imaging of cortical 11C-nicotine binding correlates with the cognitive function of attention in Alzheimer's disease. Psychopharmacology (Berl). 188, 509-520. https://doi.org/10.1007/s00213-006-0447-7

Kalmady, S. V., Agrawal, R., Venugopal, D., Shivakumar, V., Amaresha, A.C., Agarwal, S.M., Subbanna, M., Rajasekaran, A., Narayanaswamy, J.C., Debnath, M., Venkatasubramanian, G., 2018. CHRFAM7A gene expression in schizophrenia: clinical correlates and the effect of antipsychotic treatment. J. Neural Transm. 125, 741-748. https://doi.org/10.1007/s00702-017-1833-5

Kalt, W., Blumberg, J.B., McDonald, J.E., Vinqvist-Tymchuk, M.R., Fillmore, S.A.E., Graf, B.A., O'Leary, J.M., Milbury, P.E., 2008. Identification of Anthocyanins in the Liver, Eye, and Brain of Blueberry-Fed Pigs. J. Agric. Food Chem. 56, 705-712. https://doi.org/10.1021/jf071998|

Kawai, Y., 2018. Understanding metabolic conversions and molecular actions of flavonoids in vivo:toward new strategies for effective utilization of natural polyphenols in human health. J. Med. Investig. 65, 162-165.

https://doi.org/10.2152/jmi.65.162

Kim, H.-J., Lee, B.-H., Choi, S.-H., Jung, S.-W., Kim, H.-S., Hwang, S.-H., Pyo, M.-K., 
Kim, H.-C., Nah, S.-Y., 2015. Differential effects of quercetin glycosides on GABA C receptor channel activity. Arch. Pharm. Res. 38, 108-114.

https://doi.org/10.1007/s12272-014-0409-2

Koopman, W.J.H., Verkaart, S., van Emst-de Vries, S.E., Grefte, S., Smeitink, J.A.M., Willems, P.H.G.M., 2006. Simultaneous quantification of oxidative stress and cell spreading using 5-(and-6)-chloromethyl-2',7'-dichlorofluorescein. Cytom. Part A 69A, 1184-1192. https://doi.org/10.1002/cyto.a.20348

Krasieva, T.B., Ehren, J., O'Sullivan, T., Tromberg, B.J., Maher, P., 2015. Cell and brain tissue imaging of the flavonoid fisetin using label-free two-photon microscopy. Neurochem. Int. 89, 243-248.

https://doi.org/10.1016/j.neuint.2015.08.003

Kujawska, M., Jodynis-Liebert, J., 2018. Polyphenols in Parkinson's Disease: A Systematic Review of In Vivo Studies. Nutrients 10, 1-34. https://doi.org/10.3390/nu10050642

Kusano, A., Nikaido, T., Kuge, T., Ohmoto, T., Monache, G.D., Botta, B., Botta, M., Saitoh, T., 1991. Inhibition of adenosine 3',5'-cyclic monophosphate phosphodiesterase by flavonoids from licorice roots and 4-arylcoumarins. Chem. Pharm. Bull. (Tokyo). 39, 930-933. https://doi.org/10.1248/cpb.39.930

LeBel, C.P., Ischiropoulos, H., Bondy, S.C., 1992. Evaluation of the Probe 2',7'Dichlorofluorescin as an Indicator of Reactive Oxygen Species Formation and Oxidative Stress. Chem. Res. Toxicol. 5, 227-231. https://doi.org/10.1021/tx00026a012

Lee, B.-H., Choi, S.-H., Shin, T.-J., Pyo, M.K., Hwang, S.-H., Kim, B.-R., Lee, S.-M., Lee, J.-H., Kim, H.-C., Park, H.-Y., Rhim, H., Nah, S.-Y., 2010. Quercetin enhances human $\alpha 7$ nicotinic acetylcholine receptor-mediated ion current through interactions with $\mathrm{Ca}(2+)$ binding sites. Mol. Cells 30, 245-53. https://doi.org/10.1007/s10059-010-0117-9

Lee, B.-H., Choi, S.H., Shin, T.J., Pyo, M.K., Hwang, S.H., Lee, S.M., Paik, H.D., Kim, H.C., Nah, S.Y., 2011a. Effects of quercetin on a9a10 nicotinic acetylcholine receptor-mediated ion currents. Eur. J. Pharmacol. 650, 79-85. https://doi.org/10.1016/j.ejphar.2010.09.079

Lee, B.-H., Hwang, S.H., Choi, S.H., Shin, T.J., Kang, J., Lee, S.M., Nah, S.Y., 2011b. Quercetin inhibits $\alpha 3 \beta 4$ nicotinic acetylcholine receptor-mediated ion currents expressed in Xenopus oocytes. Korean J. Physiol. Pharmacol. 15, 17-22. https://doi.org/10.4196/kjpp.2011.15.1.17

Lee, B.-H., Jeong, S.M., Lee, J.H., Kim, J.H., Yoon, I.S., Choi, S.H., Lee, S.M., Chang, C.G., Kim, H.C., Han, Y., Paik, H.D., Kim, Y., Nah, S.Y., 2005. Quercetin inhibits the 5-hydroxytryptamine type 3 receptor-mediated ion current by interacting with pre-transmembrane domain I. Mol Cells 20, 69-73.

Lee, B.-H., Lee, Jun Ho, Yoon, I.S., Lee, Joon Hee, Choi, S.H., Pyo, M.K., Jeong, S.M., Choi, W.S., Shin, T.J., Lee, S.M., Rhim, H., Park, Y.S., Han, Y.S., Paik, H.D., Cho, S.G., Kim, C.H., Lim, Y.H., Nah, S.Y., 2007. Human glycine a1 receptor inhibition by quercetin is abolished or inversed by $\alpha 267$ mutations in transmembrane domain 2. Brain Res. 1161, 1-10. https://doi.org/10.1016/j.brainres.2007.05.057

Lee, B.-H., Pyo, M.K., Lee, J.-H., Choi, S.-H., Shin, T.-J., Lee, S.-M., Lim, Y., Han, Y.S., Paik, H.-D., Cho, S.-G., Yun-Choi, H.S., Rhim, H., Nah, S.-Y., 2008. Differential Regulations of Quercetin and Its Glycosides on Ligand-Gated Ion Channels. Biol. Pharm. Bull. 31, 611-617. https://doi.org/10.1248/bpb.31.611 
Lee, B.-H., Shin, T., Hwang, S., Choi, S., Kang, J., Kim, H., Park, C., Lee, S., Nah, S., 2011c. Inhibitory Effects of Quercetin on Muscle-type of Nicotinic Acetylcholine Receptor-Mediated Ion Currents Expressed in Xenopus Oocytes. Korean J. Physiol. Pharmacol. 15, 195-201. https://doi.org/10.4196/kjpp.2011.15.4.195

Lendvai, B., Kassai, F., Szájli, ágota, Némethy, Z., 2013. a7 Nicotinic acetylcholine receptors and their role in cognition. Brain Res. Bull. 93, 86-96. https://doi.org/10.1016/j.brainresbull.2012.11.003

Ma, K.G., Qian, Y.H., 2019. Alpha 7 nicotinic acetylcholine receptor and its effects on Alzheimer's disease. Neuropeptides 73, 96-106. https://doi.org/10.1016/j.npep.2018.12.003

Mazzaferro, S., Benallegue, N., Carbone, A.L., Gasparri, F., Vijayan, R., Biggin, P.C., Moroni, M., Bermudez, I., 2011. Additional Acetylcholine (ACh) binding site at a4/a4 interface of ( $\alpha 4 \beta 2) 2 \alpha 4$ nicotinic receptor influences agonist sensitivity. J. Biol. Chem. 286, 31043-31054. https://doi.org/10.1074/jbc.M111.262014

Milbury, P.E., Kalt, W., 2010. Xenobiotic Metabolism and Berry Flavonoid Transport across the Blood-Brain Barrier. J. Agric. Food Chem. 58, 3950-3956. https://doi.org/10.1021/jf903529m

Navarro, E., Buendia, I., Parada, E., León, R., Jansen-Duerr, P., Pircher, H., Egea, J., Lopez, M.G., 2015. Alpha7 nicotinic receptor activation protects against oxidative stress via heme-oxygenase I induction. Biochem. Pharmacol. 97, 473-481. https://doi.org/10.1016/j.bcp.2015.07.022

Navarro, E., Gonzalez-Lafuente, L., Pérez-Liébana, I., Buendia, I., López-Bernardo, E., Sánchez-Ramos, C., Prieto, I., Cuadrado, A., Satrustegui, J., Cadenas, S., Monsalve, M., López, M.G., 2016. Heme-Oxygenase I and PCG-1a Regulate Mitochondrial Biogenesis via Microglial Activation of Alpha7 Nicotinic Acetylcholine Receptors Using PNU282987 . Antioxid. Redox Signal. 27, 93-105. https://doi.org/10.1089/ars.2016.6698

Ng, H.J., Hogenkamp, D.J., Stevens, K.E., Gee, K.W., Zheng, L., Tran, M.B., Johnstone, T.B., Broide, R.S., Whittemore, E.R., 2007. Nootropic $\alpha 7$ nicotinic receptor allosteric modulator derived from GABAA receptor modulators. Proc. Natl. Acad. Sci. 104, 8059-8064. https://doi.org/10.1073/pnas.0701321104

Nielsen, B.E., Minguez, T., Bermudez, I., Bouzat, C., 2018. Molecular function of the novel $\alpha 7 \beta 2$ nicotinic receptor. Cell. Mol. Life Sci. 75, 2457-2471. https://doi.org/10.1007/s00018-017-2741-4

Pałczynska, M.M., Jindrichova, M., Gibb, A.J., Millar, N.S., 2012. Activation of a7 Nicotinic Receptors by Orthosteric and Allosteric Agonists : Influence on SingleChannel Kinetics and Conductance. Mol Pharmacol 82, 910-917. https://doi.org/10.1124/mol.112.080259

Panche, A.N., Diwan, A.D., Chandra, S.R., 2016. Flavonoids: an overview. J. Nutr. Sci. 5, 1-15. https://doi.org/10.1017/jns.2016.41

Papke, R.L., Papke, J.K.P., 2002. Comparative pharmacology of rat and human $\alpha 7$ nAChR conducted with net charge analysis. Br. J. Pharmacol. 137, 49-61. https://doi.org/10.1038/sj.bjp.0704833

Parada, E., Egea, J., Buendia, I., Negredo, P., Cunha, A.C., Cardoso, S., Soares, M.P., López, M.G., 2013. The Microglial a7-Acetylcholine Nicotinic Receptor Is a Key Element in Promoting Neuroprotection by Inducing Heme Oxygenase-1 via Nuclear Factor Erythroid-2-Related Factor 2. Antioxid. Redox Signal. 19, 1135- 
1148. https://doi.org/10.1089/ars.2012.4671

Parada, E., Egea, J., Romero, A., García, A.G., López, M.G., 2010. Free Radical Biology \& Medicine Poststress treatment with PNU282987 can rescue SH-SY5Y cells undergoing apoptosis via $\alpha 7$ nicotinic receptors linked to a Jak2 / Akt / HO-1 signaling pathway. Free Radic. Biol. Med. 49, 1815-1821. https://doi.org/10.1016/j.freeradbiomed.2010.09.017

Park, H.J., Lee, P.H., Ahn, Y.W., Choi, Y.J., Lee, G., Lee, D.Y., Chung, E.S., Jin, B.K., 2007. Neuroprotective effect of nicotine on dopaminergic neurons by antiinflammatory action. Eur. J. Neurosci. 26, 79-89. https://doi.org/10.1111/j.14609568.2007.05636.x

Qian, Y., Cao, L., Guan, T., Chen, L., Xin, H., Li, Y., Qian, Y., Cao, L., Guan, T., Chen, L., Xin, H., Li, Y., Zheng, R., Yu, D., 2015. Protection by genistein on cortical neurons against oxidative stress injury via inhibition of NF-kappaB, JNK and ERK signaling pathway Protection by genistein on cortical neurons against oxidative stress injury via inhibition of NF-kappaB, JNK and ERK s 0209. https://doi.org/10.3109/13880209.2014.962057

Rayes, D., Spitzmaul, G., Sine, S.M., Bouzat, C., 2005. Single-channel kinetic analysis of chimeric alpha7-5HT3A receptors. Mol. Pharmacol. 68, 1475-83. https://doi.org/10.1124/mol.105.015438

Rego Campello, H., Del Villar, S.G., Honraedt, A., Minguez, T., Oliveira, A.S.F., Ranaghan, K.E., Shoemark, D.K., Bermudez, I., Gotti, C., Sessions, R.B., Mulholland, A.J., Wonnacott, S., Gallagher, T., 2018. Unlocking Nicotinic Selectivity via Direct C-H Functionalization of (-)-Cytisine. Chem 4, 1710-1725. https://doi.org/10.1016/j.chempr.2018.05.007

Rossi, L., Mazzitelli, S., Arciello, M., Capo, C.R., Rotilio, G., 2008. Benefits from dietary polyphenols for brain aging and Alzheimer's disease. Neurochem. Res. 33, 23902400. https://doi.org/10.1007/s11064-008-9696-7

Schaffer, S., Halliwell, B., 2012. Do polyphenols enter the brain and does it matter? Some theoretical and practical considerations. Genes Nutr. 7, 99-109. https://doi.org/10.1007/s12263-011-0255-5

Schieber, M., Chandel, N.S., 2014. ROS function in redox signaling and oxidative stress. Curr. Biol. 24, 453-462. https://doi.org/10.1016/j.cub.2014.03.034

Sepúlveda, M., Gonano, L.A., Back, T.G., Chen, S.R.W., Vila Petroff, M., 2013. Role of CaMKII and ROS in rapid pacing-induced apoptosis. J. Mol. Cell. Cardiol. 63, 135-145. https://doi.org/10.1016/j.yjmcc.2013.07.013

Shen, J.X., Yakel, J.L., 2012. Functional $\alpha 7$ nicotinic ACh receptors on astrocytes in rat hippocampal CA1 slices. J. Mol. Neurosci. 48, 14-21.

https://doi.org/10.1007/s12031-012-9719-3

Shin, T.-J., Choi, S.-H., Lee, B.-H., Pyo, M.K., Hwang, S.-H., Kim, B.-R., Lee, S.-M., Han, Y.S., Lee, J.-H., Park, J.-H., Kim, H.-C., Rhim, H., Nah, S.-Y., 2010. Effects of Quercetin on Human a-Amino-3-hydroxy-5-methyl-4- isoxazolepropionic Acid Receptor-Mediated Ion Currents. Biol. Pharm. Bull. 33, 1615-1619. https://doi.org/10.1248/bpb.33.1615

Shytle, R.D., Mori, T., Townsend, K., Vendrame, M., Sun, N., Zeng, J., Ehrhart, J., Silver, A.A., Sanberg, P.R., Tan, J., 2004. Cholinergic modulation of microglial activation by $\alpha 7$ nicotinic receptors. J. Neurochem. 89, 337-343.

https://doi.org/10.1046/j.1471-4159.2004.02347.x 
Spencer, J.P.E., Vafeiadou, K., Williams, R.J., Vauzour, D., 2012. Neuroinflammation: Modulation by flavonoids and mechanisms of action. Mol. Aspects Med. 33, 8397. https://doi.org/10.1016/j.mam.2011.10.016

Spencer, J.P.E., Vauzour, D., Rendeiro, C., 2009. Flavonoids and cognition : The molecular mechanisms underlying their behavioural effects. Arch. Biochem. Biophys. 492, 1-9. https://doi.org/10.1016/j.abb.2009.10.003

Targowska-Duda, K.M., Kaczor, A.A., Jozwiak, K., Arias, H.R., 2018. Molecular interactions of type I and type II positive allosteric modulators with the human $\alpha 7$ nicotinic acetylcholine receptor: an in silico study. J. Biomol. Struct. Dyn. 1102, 129. https://doi.org/10.1080/07391102.2018.1427634

Thomsen, M.S., Hansen, H.H., Timmerman, D.B., Mikkelsen, J.D., 2010. Cognitive improvement by activation of $\alpha 7$ nicotinic acetylcholine receptors: from animal models to human pathophysiology. Curr. Pharm. Des. 16, 323-343. https://doi.org/10.2174/138161210790170094

Tregellas, J.R., Wylie, K.P., 2019. Alpha7 Nicotinic Receptors as Therapeutic Targets in Schizophrenia. Nicotine Tob. Res. 21, 349-356. https://doi.org/10.1093/ntr/nty034

Tsoyi, K., Chung, H.-T., Pae, H., Kim, H.J., Jang, H.J., Kim, J.W., Chang, H.K., Chang, K.C., Lee, J.H., Seo, H.G., Lee, Y.S., 2011. Stimulation of Alpha7 Nicotinic Acetylcholine Receptor by Nicotine Attenuates Inflammatory Response in Macrophages and Improves Survival in Experimental Model of Sepsis Through Heme Oxygenase-1 Induction. Antioxid. Redox Signal. 14, 2057-2070. https://doi.org/10.1089/ars.2010.3555

Ulubelen, A., Kerr, R.R., Mabry, T.J., 1982. Two new neoflavonoids and Cglycosylflavones from Passiflora serratodigitata. Phytochemistry 21, 1145-1147. https://doi.org/10.1016/S0031-9422(00)82434-6

Unno, K., Pervin, M., Nakagawa, A., Iguchi, K., Hara, A., Takagaki, A., Nanjo, F., Minami, A., Nakamura, Y., 2017. Blood-Brain Barrier Permeability of Green Tea Catechin Metabolites and their Neuritogenic Activity in Human Neuroblastoma SHSY5Y Cells. Mol. Nutr. Food Res. 61, 1-18. https://doi.org/10.1002/mnfr.201700294

Uteshev, V., 2016. Are positive allosteric modulators of $\alpha 7 \mathrm{nAChRs}$ clinically safe? J. Neurochem. 136, 217-219. https://doi.org/10.1111/jnc.13236

Uteshev, V. V., 2014. The therapeutic promise of positive allosteric modulation of nicotinic receptors. Eur. J. Pharmacol. 727, 181-185. https://doi.org/10.1016/j.ejphar.2014.01.072

Vauzour, D., Martinsen, A., Layé, S., 2015. Neuroinflammatory processes in cognitive disorders: Is there a role for flavonoids and n-3 polyunsaturated fatty acids in counteracting their detrimental effects? Neurochem. Int. 89, 63-74. https://doi.org/10.1016/j.neuint.2015.08.004

Veselinović, J.B., Veselinović, A.M., Ilic-Tomic, T., Davis, R., O'Connor, K., Pavic, A., Nikodinovic-Runic, J., 2017. Potent anti-melanogenic activity and favorable toxicity profile of selected 4-phenyl hydroxycoumarins in the zebrafish model and the computational molecular modeling studies. Bioorganic Med. Chem. 25, 62866296. https://doi.org/10.1016/j.bmc.2017.09.021

Veselinović, J.B., Veselinović, A.M., Nikolić, G.M., Pešić, S.Z., Stojanović, D.B., Matejić, J.S., Mihajilov-Krstev, T.M., 2015. Antibacterial potential of selected 4- 
phenyl hydroxycoumarins: Integrated in vitro and molecular docking studies. Med. Chem. Res. 24, 1626-1634. https://doi.org/10.1007/s00044-014-1245-0

Veselinović, J.B., Veselinović, A.M., Vitnik, Ž.J., Vitnik, V.D., Nikolić, G.M., 2014. Antioxidant properties of selected 4-phenyl hydroxycoumarins: Integrated in vitro and computational studies. Chem. Biol. Interact. 214, 49-56. https://doi.org/10.1016/j.cbi.2014.02.010

Wasowski, C., Marder, M., 2012. Flavonoids as GABAA receptor ligands: the whole story? J. Exp. Pharmacol. 4, 9-24. https://doi.org/10.2147/JEP.S23105

Williams, D.K., Peng, C., Kimbrell, M.R., Papke, R.L., 2012. Intrinsically Low Open Probability of $\alpha 7$ Nicotinic Acetylcholine Receptors Can Be Overcome by Positive Allosteric Modulation and Serum Factors Leading to the Generation of Excitotoxic Currents at Physiological Temperatures. Mol. Pharmacol. 82, 746-759. https://doi.org/10.1124/mol.112.080317

Williams, D.K., Wang, J., Papke, R.L., 2011. Positive allosteric modulators as an approach to nicotinic acetylcholine receptor-targeted therapeutics: Advantages and limitations. Biochem. Pharmacol. 82, 915-930. https://doi.org/10.1016/j.bcp.2011.05.001

Williams, R.J., Spencer, J.P.E., Rice-Evans, C., 2004. Flavonoids: Antioxidants or signalling molecules? Free Radic. Biol. Med. 36, 838-849. https://doi.org/10.1016/j.freeradbiomed.2004.01.001

Yang, T., Xiao, T., Sun, Q., Wang, K., 2017. The current agonists and positive allosteric modulators of $\alpha 7 \mathrm{nAChR}$ for CNS indications in clinical trials. Acta Pharm. Sin. B 7, 611-622. https://doi.org/10.1016/j.apsb.2017.09.001

Young, G.T., Zwart, R., Walker, A.S., Sher, E., Millar, N.S., 2008. Potentiation of $\alpha 7$ nicotinic acetylcholine receptors via an allosteric transmembrane site. Proc. Natl. Acad. Sci. U. S. A. 105, 14686-14691. https://doi.org/10.1073/pnas.0804372105

Zanetti, S.R., Ziblat, A., Torres, N.I., Zwirner, N.W., Bouzat, C., 2016. Expression and Functional Role of $\alpha 7$ Nicotinic Receptor in Human Cytokine-stimulated Natural Killer (NK) Cells. J. Biol. Chem. 291, 16541-16552. https://doi.org/10.1074/jbc.M115.710574

Zwart, R., De Filippi, G., Broad, L.M., McPhie, G.I., Pearson, K.H., Baldwinson, T., Sher, E., 2002. 5-Hydroxyindole potentiates human alpha 7 nicotinic receptormediated responses and enhances acetylcholine-induced glutamate release in cerebellar slices. Neuropharmacology 43, 374-84. https://doi.org/10.1016/S00283908(02)00094-1 


\section{FIGURE LEGENDS}

Figure 1. Effects of flavonoids on macroscopic currents of human $\alpha 7$ evoked by ACh in Xenopus oocytes.

(A) Left: Chemical structures of flavonoids: Genistein (Gen), Quercetin (Que) and 5,7dihydroxy-4-phenylcoumarin ( $\mathrm{Neo}$ ), showing the benzopyrone moiety (A and C-rings) and the position in which B-ring is located for each class. Right: Representative traces of macroscopic currents evoked by $\mathrm{ACh}$ at a concentration corresponding to $\mathrm{EC}_{20}$ (30 $\mu \mathrm{M})$ alone (control currents, grey) and together with the flavonoid at different concentrations (experimental currents, coloured traces, co-application protocol). Currents were recorded from Xenopus oocytes at $60 \mathrm{mV}$ holding potential using HiClamp.

(B) Concentration-response curves obtained from macroscopic currents elicited by ACh $(30 \mu \mathrm{M})$ in the presence of different concentrations of Gen (red), Que (blue) and Neo (green) were fitted by nonlinear regression to the Hill Equation, as described in Materials and Methods. The two plots correspond to different protocols: co-application, in which flavonoids were applied with the agonist (left) or preincubation plus coapplication, in which cells were preincubated for $10 \mathrm{~s}$ with the flavonoid and then the flavonoid was applied together with the agonist (right). Data points are mean values \pm SEM. $E_{50}$ values, maximal potentiation, Hill slope and the number of independent experiments $(n)$ and batches of oocytes $(N)$ are shown in Table 1.

\section{Figure 2. Potentiation and recovery from desensitization of human $\alpha 7$ by} flavonoids and typical PAMs.

(A) Macroscopic currents were recorded in the whole-cell configuration from BOSC23 cells expressing human $\alpha 7$. Top: Representative whole-cell $\alpha 7$-currents evoked by ACh (black traces) and ACh co-applied with the prototype type I PAM (5-HI) and type II PAM (PNU-120596) (grey traces). Bottom: Representative whole-cell $\alpha 7$-currents elicited by ACh (black traces) and by ACh co-applied with a given flavonoid (grey traces). The horizontal bars over the currents indicate the application of agonist alone (black) or together with PAMs or flavonoids (grey). Holding potential: $50 \mathrm{mV}$.

(B) Recovery of $\alpha 7$ from desensitization by PAMs and flavonoids was assessed. Continuous exposure of $\alpha 7$ to $\mathrm{ACh}(100 \mu \mathrm{M})$ results in $\alpha 7$ desensitization. After reaching the steady state current in the continuous presence of $A C h$, cells were exposed to a pulse of buffer alone or containing different drugs: type II PAM ( $1 \mu \mathrm{M}$ PNU-120596) and type I PAMs (2 mM 5-HI and $10 \mu \mathrm{M}$ NS-1738) (left) and flavonoids Gen, Que and Neo $(50 \mu \mathrm{M})$ (right). The traces shown are representative for each 
condition. The control currents evoked by ACh (black traces) were normalized among the different conditions for comparison of the reactivated currents (grey traces). The horizontal bars over the currents indicate the application of agonist alone (black) or together with buffer or drugs (grey). Holding potential: $50 \mathrm{mV}$.

Figure 3. Single-channel current profile of $\alpha 7$ in the presence of flavonoids.

Single-channel currents were recorded in the cell-attached configuration from BOSC23 cells expressing human $\alpha 7$.

(A) Left: Typical traces of $\alpha 7$ channel currents in the presence of $100 \mu \mathrm{M}$ ACh alone or combined with $50 \mu \mathrm{M}$ Gen, $50 \mu \mathrm{M}$ Que and $50 \mu \mathrm{M}$ Neo. Channel openings are shown as upward deflections. Right: Representative open and burst duration histograms for each condition. Membrane potential: $-70 \mathrm{mV}$. Filter: $9 \mathrm{kHz}$.

(B) Mean open $\left(\tau_{\text {open }}\right)$ and burst ( $\left.\tau_{\text {burst }}\right)$ durations in presence of $50 \mu \mathrm{M}$ Gen, $50 \mu \mathrm{M}$ Que and $50 \mu \mathrm{M}$ Neo. The data correspond to the duration of the slowest component of each corresponding histogram. Data are plotted as mean \pm SD. The $n$ (number of independent experiments) for each condition was: (-) $n=5$, Gen $n=5$, Que $n=4$ and Neo $\mathrm{n}=4$. The number of cell transfections $(\mathrm{N})$ for each condition is shown in Table 2.

Statistical significance among groups was determined by OneWay ANOVA followed by Bonferroni's post-hoc tests for multiple comparisons. The symbol * indicates differences with control without flavonoid, \# indicates differences with Gen condition and \& indicates differences with Que condition. ns indicates no significant differences among the conditions. For all the cases, the number of symbols (one, two or three) indicates different significant $p$-values independently of the type of symbol (For instance, $\left.p<0.05^{\star}, p<0.01^{* *}, p<0.001^{* * *}\right)$.

Figure 4. Effects of flavonoids on chimeric $\alpha 7-5 \mathrm{HT}_{3} \mathrm{~A}$ receptors at the singlechannel level.

(A) Left: Typical traces from single-channel recordings of chimeric $\alpha 7-5 \mathrm{HT}_{3} \mathrm{~A}$ in the presence of $500 \mu \mathrm{M}$ ACh alone or combined with $50 \mu \mathrm{M}$ Gen, $50 \mu \mathrm{M}$ Que or $50 \mu \mathrm{M}$ Neo. Channel openings are shown as upward deflections. Right: Representative open and burst duration histograms for each condition. Membrane potential: $-70 \mathrm{mV}$. Filter: 9 $\mathrm{kHz}$.

(B) Mean open $\left(\tau_{\text {open }}\right)$ and burst $\left(\tau_{\text {burst }}\right)$ durations in presence of $50 \mu \mathrm{M}$ Gen, $50 \mu \mathrm{M}$ Que and $50 \mu \mathrm{M}$ Neo. The data correspond to the duration of the slowest component of each corresponding histogram. Data are plotted as mean \pm SD. The $n$ (number of independent experiments) for each condition was: (-) $n=5$, Gen $n=4$, Que $n=5$ and Neo 
$\mathrm{n}=4$. The number of cell transfections $(\mathrm{N})$ for each condition is shown in Table 2 . Statistical significance was determined by two-tailed Student's t-test. The symbol * indicates statistically significant differences with control without flavonoid.

Figure 5. Effects of flavonoids on the quintuple mutant $\alpha 7$ TSLMF at the singlechannel level.

(A) View of the $\alpha$-helices TM1, TM2 and TM3 with the five mutations that make $\alpha 7$ insensitive to PNU-120596 (DaCosta et al., 2011).

(B) Left: Typical traces from single-channel recordings of $\alpha 7$ TSLMF in the presence of $100 \mu \mathrm{M}$ ACh alone or combined with $50 \mu \mathrm{M}$ Gen, $50 \mu \mathrm{M}$ Que and $50 \mu \mathrm{M}$ Neo. Channel openings are shown as upward deflections. Right: Representative open and burst duration histograms for each condition. Membrane potential: $-70 \mathrm{mV}$. Filter: $9 \mathrm{kHz}$.

(C) Mean open $\left(\tau_{\text {open }}\right)$ and burst $\left(\tau_{\text {burst }}\right)$ durations in presence of $50 \mu \mathrm{M}$ Gen, $50 \mu \mathrm{M}$ Que and $50 \mu \mathrm{M}$ Neo. Data are plotted as mean \pm SD. The number of independent experiments ( $n$ ) for each condition was: $(-) n=5$, Gen $n=4$, Que $n=5$ and Neo $n=4$. The number of cell transfections $(\mathrm{N})$ for each condition is shown in Table 2. Statistical significance was determined by two-tailed Student's t-test. The symbol * indicates comparison with control without flavonoid.

Figure 6. Effects of flavonoids on intracellular ROS production.

24-h treatment (A-C) (A) Representative fluorescence images of the effects on intracellular ROS levels after $24 \mathrm{~h}$ treatment with flavonoids alone $(50 \mu \mathrm{M}), 10 \mu \mathrm{M}$ PNU-282987 (selective agonist), $500 \mathrm{nM} \alpha$-Bgt (selective antagonist), $10 \mu \mathrm{M}$ PNU282987 plus $500 \mathrm{nM} \alpha$-Bgt, and flavonoids $(50 \mu \mathrm{M})$ plus $10 \mu \mathrm{M}$ PNU-282987. The DCF fluorescence was observed under an inverted fluorescence microscope. Scale bar: 50 $\mu \mathrm{m}$.

(B) The plot shows the mean curves describing time course of ROS production for each condition after 24 h-treatment fitted by linear regression: control, $50 \mu \mathrm{M}$ Gen, 50 $\mu \mathrm{M}$ Que, $50 \mu \mathrm{M}$ Neo, $10 \mu \mathrm{M}$ PNU-282987, 500 nM $\alpha$-Bgt, $10 \mu \mathrm{M}$ PNU-282987 + 500 nM $\alpha$-Bgt, $10 \mu \mathrm{M}$ PNU-282987 + $50 \mu \mathrm{M}$ Gen, $10 \mu \mathrm{M}$ PNU-282987 + $50 \mu \mathrm{M}$ Que and 10 $\mu \mathrm{M}$ PNU-282987 + $50 \mu \mathrm{M}$ Neo. The curves corresponding to the positive control with $\mathrm{H}_{2} \mathrm{O}_{2}$ (added at time zero of the assay) and to the dye control (solution of the probe alone) are also shown. Data are plotted as mean \pm SEM, normalizing the slope of each condition to the slope of the control condition. For clarity reasons, we refer to PNU282987 ( $\alpha 7$ selective agonist) as PNU in the figure. 
(C) The bar chart shows the normalized DCF slope (ROS generation rate) obtained from the previous plot in the different conditions after $24 \mathrm{~h}$-exposure. Data are plotted as mean $\pm S D$. The number of independent experiments $(n)$ were: DMSO control $n=11$, Gen $n=5$, Que $n=5$, Neo $n=5$, PNU-282987 $n=11, \alpha$-Bgt $n=9$, PNU-282987 $+\alpha$-Bgt $\mathrm{n}=9, \mathrm{PNU}-282987+$ Gen $\mathrm{n}=5, \mathrm{PNU}-282987+$ Que $\mathrm{n}=5$ and PNU-282987 + Neo $\mathrm{n}=5$. The number of cell transfections $(N)$ coincides with the number of independent experiments $(n)$ for each condition. The symbol * indicates comparison to the DMSO control by two-tailed Student's t-test. For clarity reasons, we refer to PNU-282987 ( $\alpha 7$ selective agonist) as PNU in the figure. The slope corresponding to cells treated with $\mathrm{H}_{2} \mathrm{O}_{2}$ is shown for comparative purposes.

12-h treatment (D-E) (D) Representative fluorescence images of the effects of $50 \mu \mathrm{M}$ Gen, $10 \mu \mathrm{M}$ PNU-282987, $10 \mu \mathrm{M}$ PNU-282987 + $50 \mu \mathrm{M}$ Gen and $10 \mu \mathrm{M}$ PNU-282987 $+50 \mu \mathrm{M}$ Gen $+500 \mathrm{nM} \alpha$-Bgt on intracellular ROS levels after $12 \mathrm{~h}$ treatment. The DCF fluorescence was observed under an inverted microscope. Scale bar: $50 \mu \mathrm{m}$.

(E) The bar chart shows the normalized DCF slope (ROS generation rate) in the different conditions after $12 \mathrm{~h}$-exposure. Data are plotted as mean $\pm \mathrm{SD}$. The number of independent experiments ( $\mathrm{n}$ ) were: DMSO control $\mathrm{n}=7,10 \mu \mathrm{M}$ Gen $\mathrm{n}=7,50 \mu \mathrm{M}$ Gen $\mathrm{n}=7$, PNU-282987 n=7, PNU-282987 + $10 \mu \mathrm{M}$ Gen $\mathrm{n}=7$, PNU-282987 + $50 \mu \mathrm{M}$ Gen $\mathrm{n}=7, \mathrm{PNU}-282987+10 \mu \mathrm{M}$ Gen $+\alpha$-Bgt $\mathrm{n}=3$ and PNU-282987 $+50 \mu \mathrm{M}$ Gen $+\alpha$-Bgt $n=3$. The number of cell transfections $(N)$ coincides with the number of independent experiments $(n)$ for each condition. The symbol * indicates comparison to the DMSO control, by two-tailed Student's t-test. For clarity reasons, we refer to PNU-282987 ( $\alpha 7$ selective agonist) as PNU in the figure. 


\section{FIGURES}

Figure 1

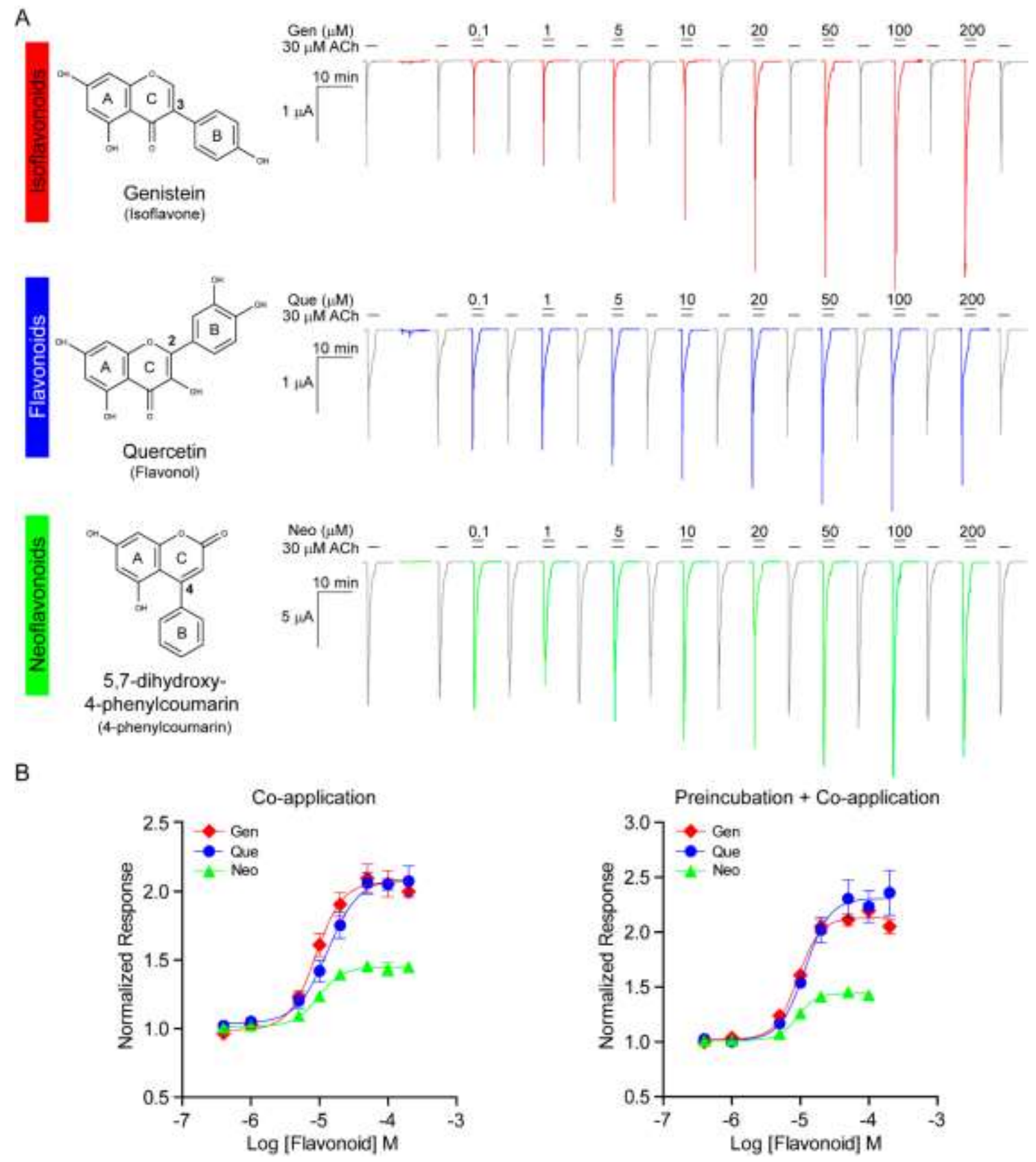


Figure 2

A

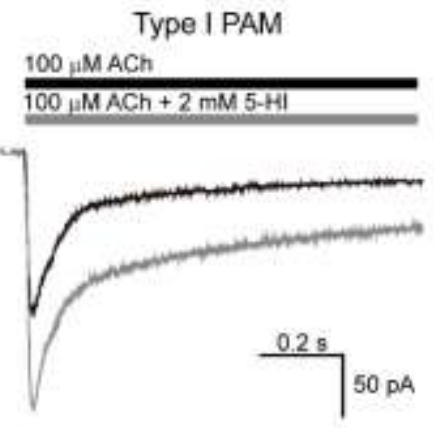

Type II PAM

$100 \mu \mathrm{MACh}$

100 MACC + 11M PNU-120596

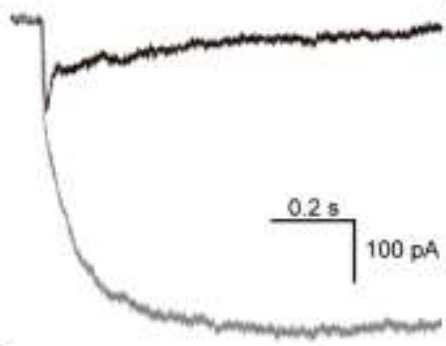

Flavonoids
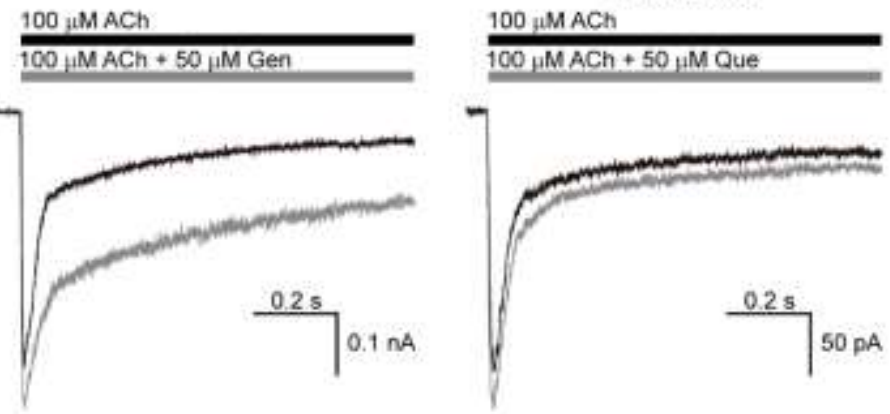

$100 \mathrm{MMACh}$

100 pMACh +50 y.M Neo

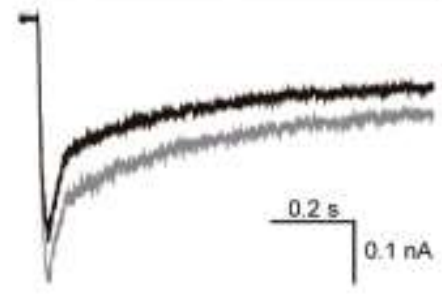

B
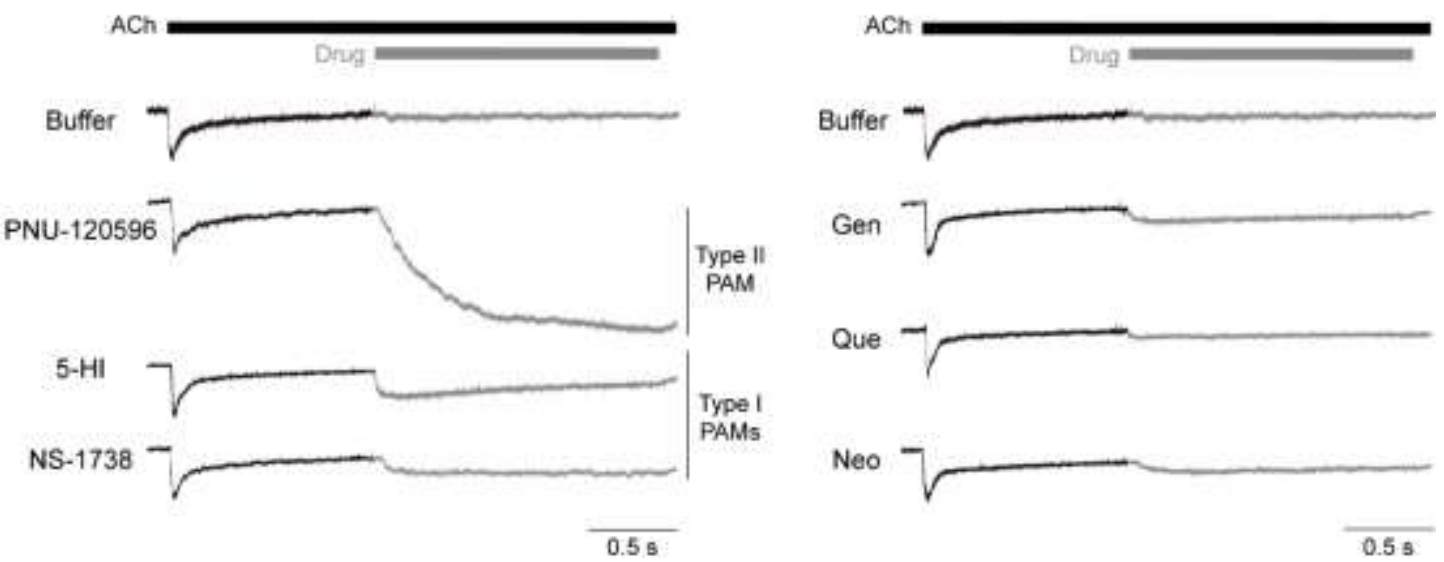

Neo

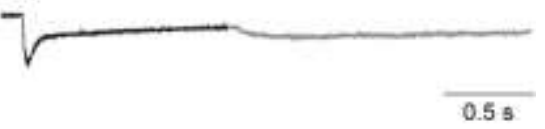




\section{Figure 3}

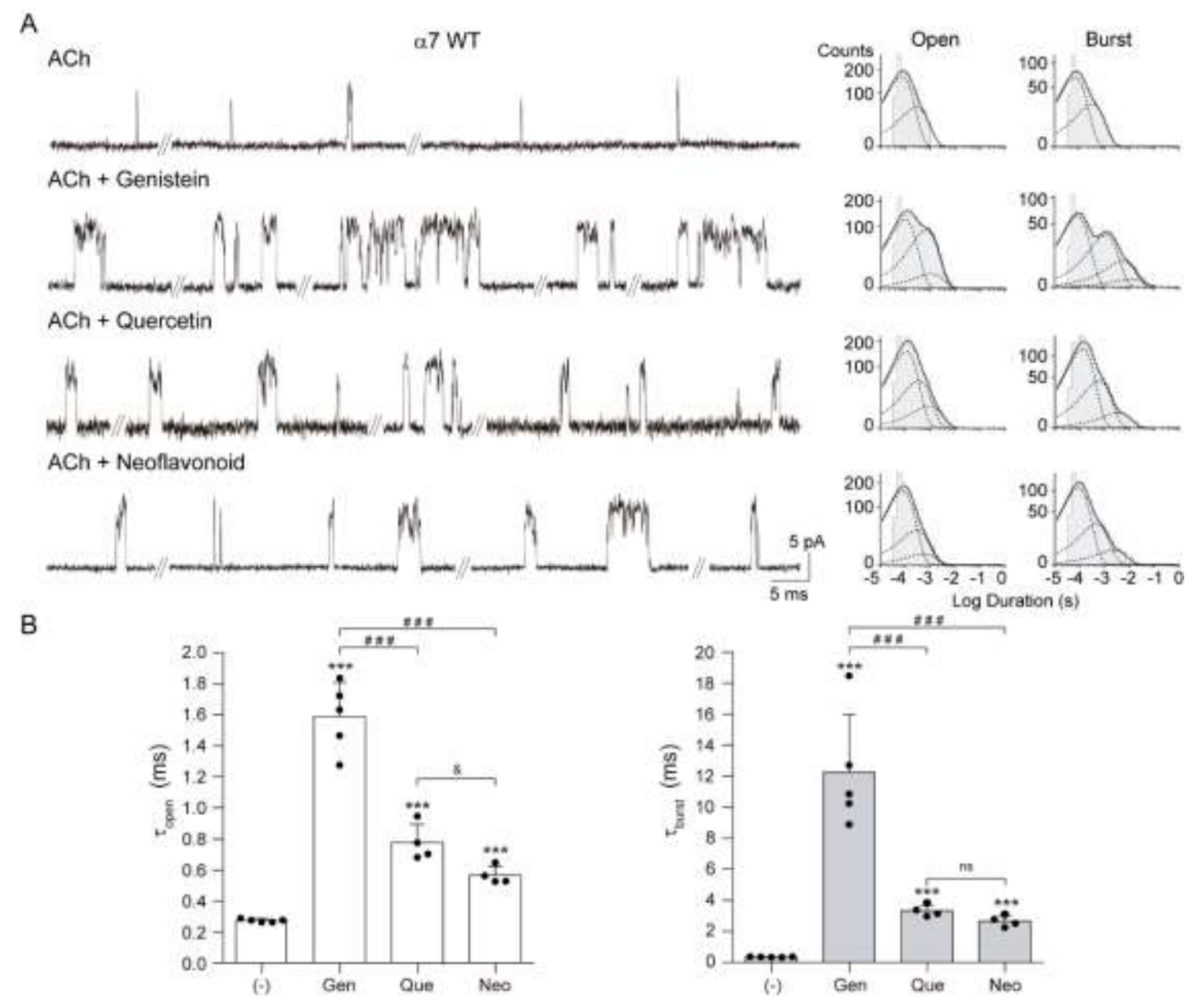


Figure 4

A

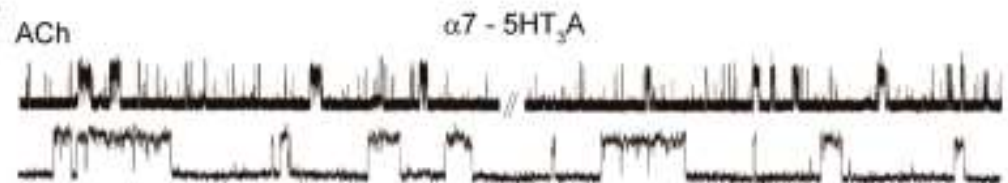
$\mathrm{ACh}+$ Genistein

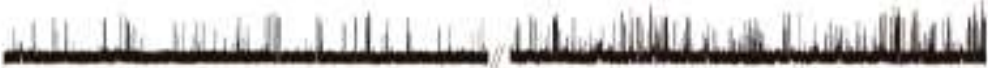

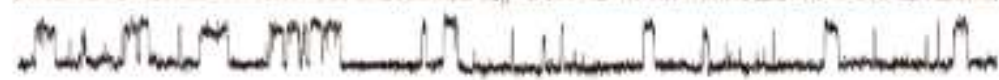

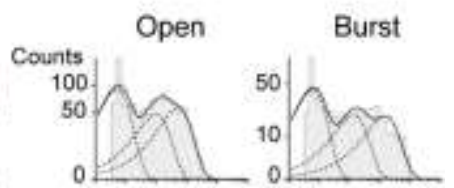
$\mathrm{ACh}+$ Quercetin

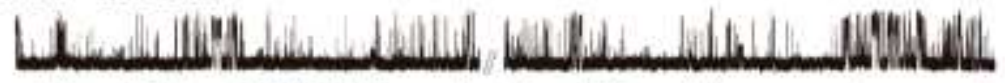

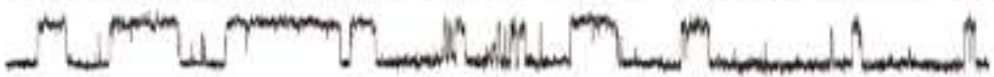

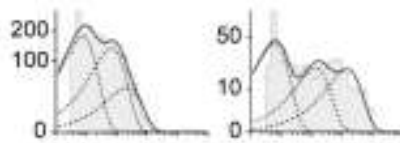
ACh + Neoflavonoid

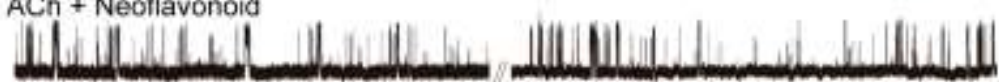
- "in-" -

B
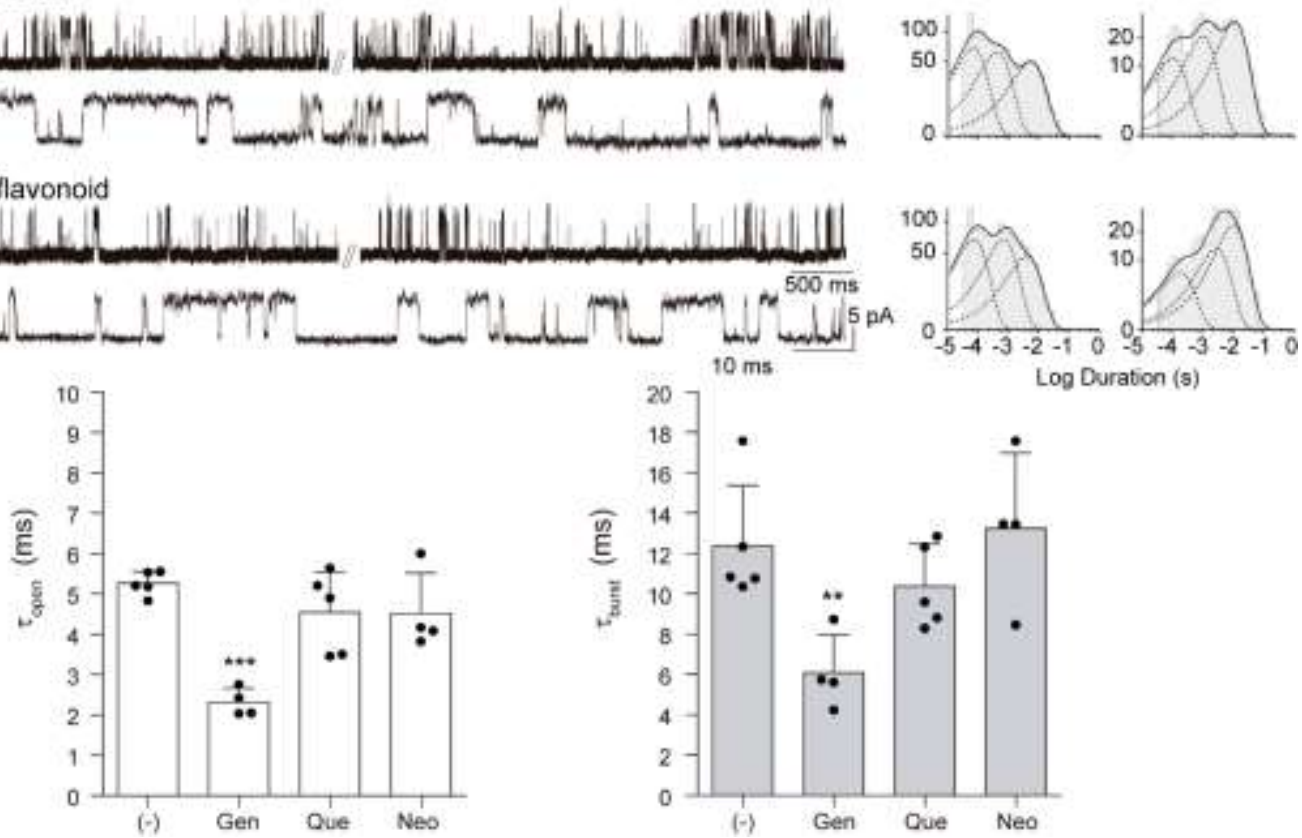
Figure 5

A

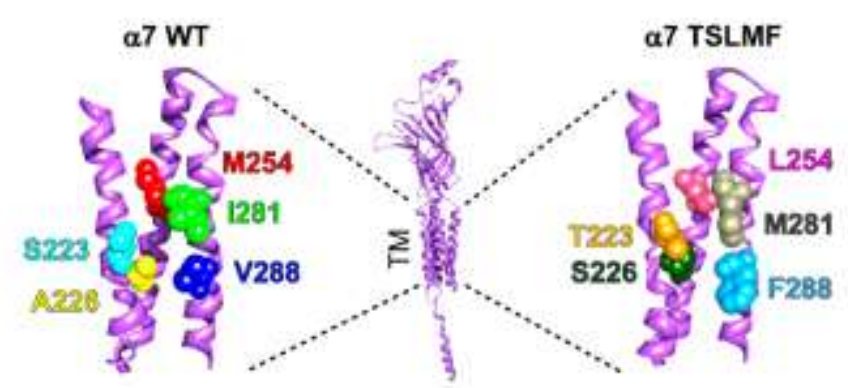

B
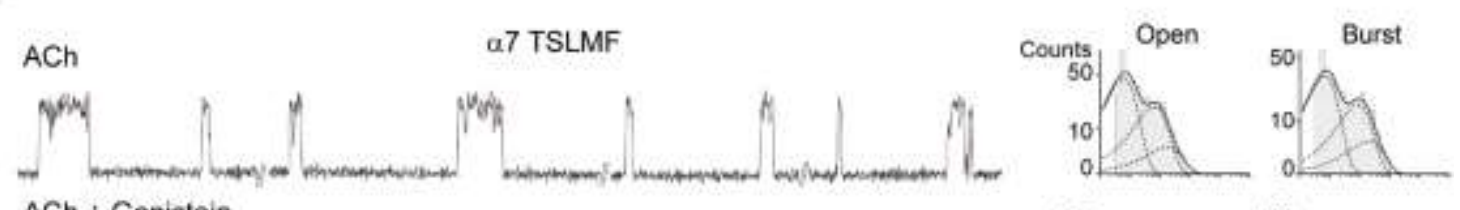

$\mathrm{ACh}+$ Genistein
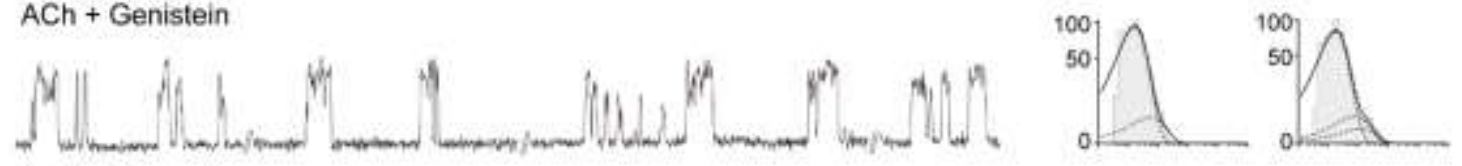

$\mathrm{ACh}+$ Quercetin
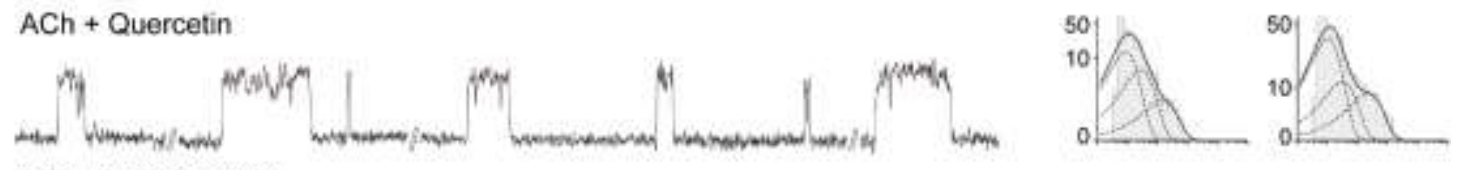

$\mathrm{ACh}+$ Neoflavonoid
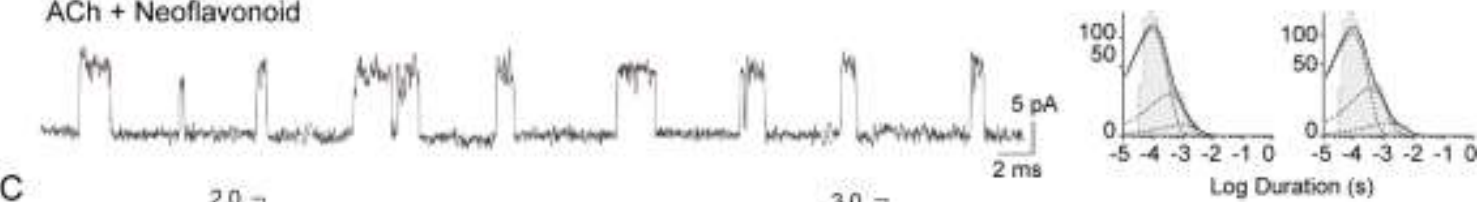

C
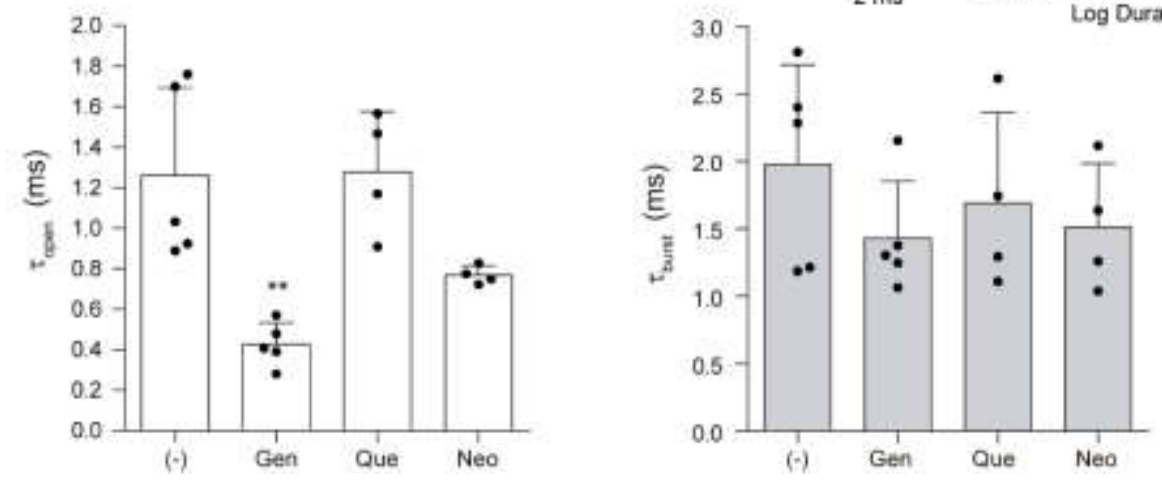


\section{Figure 6}

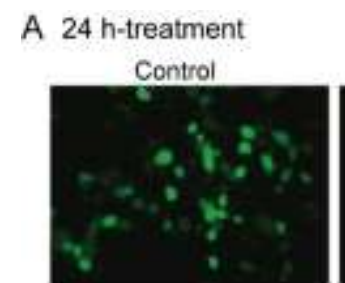

$\alpha-\mathrm{Bgt}$
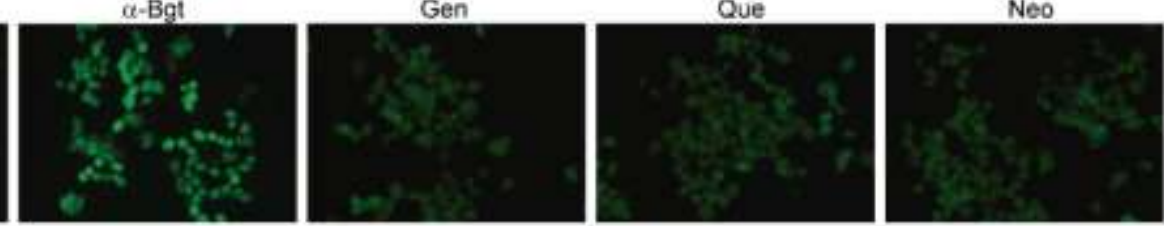

PNU

$\mathrm{PNU}+\alpha-\mathrm{Bgt}$

$\mathrm{PNU}+\mathrm{Gen}$
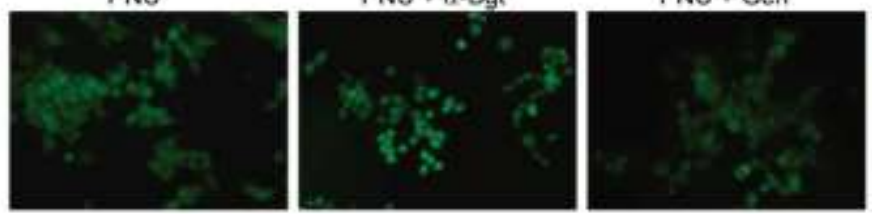

$\mathrm{PNU}+$ Que

$\mathrm{PNU}+\mathrm{NeO}$
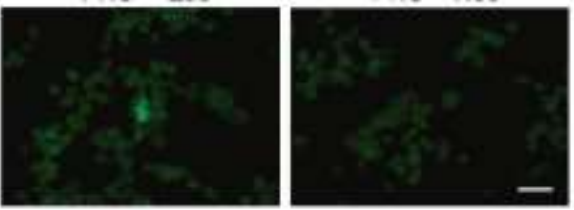

B

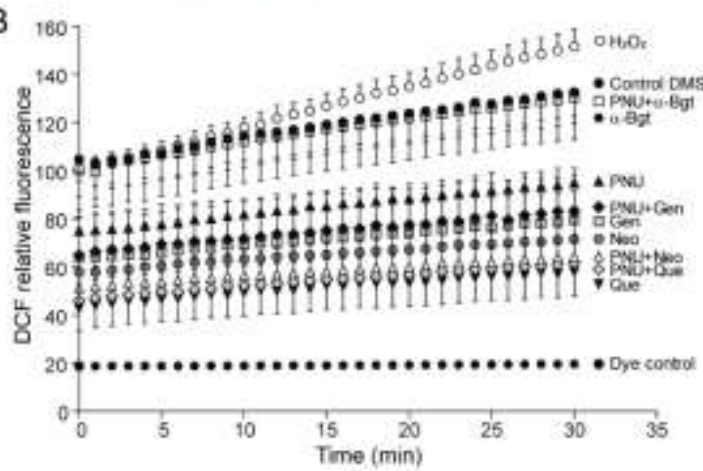

C 257

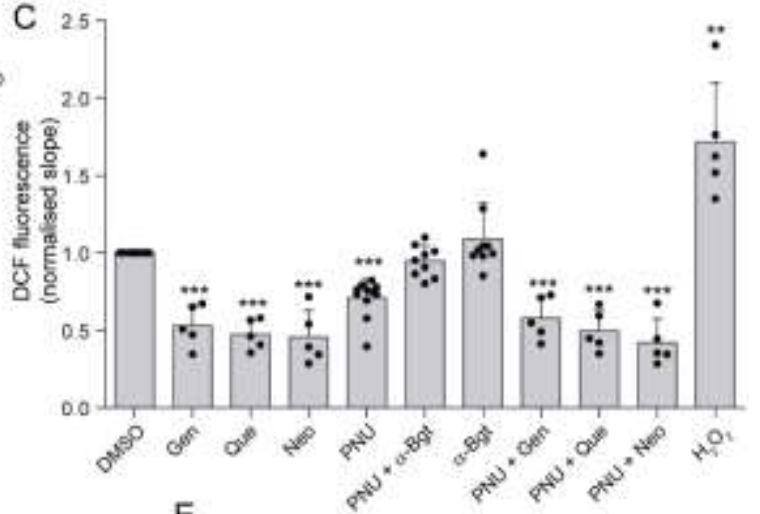

D $12 \mathrm{~h}$-treatment

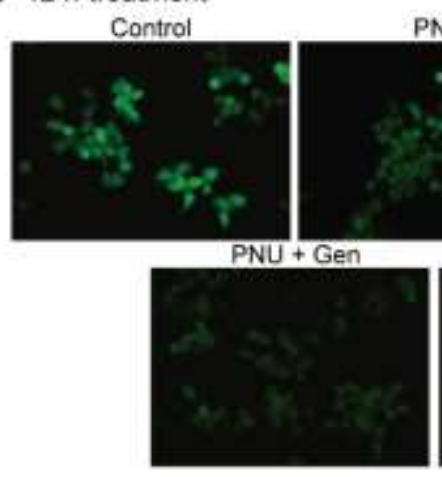
PNU

E

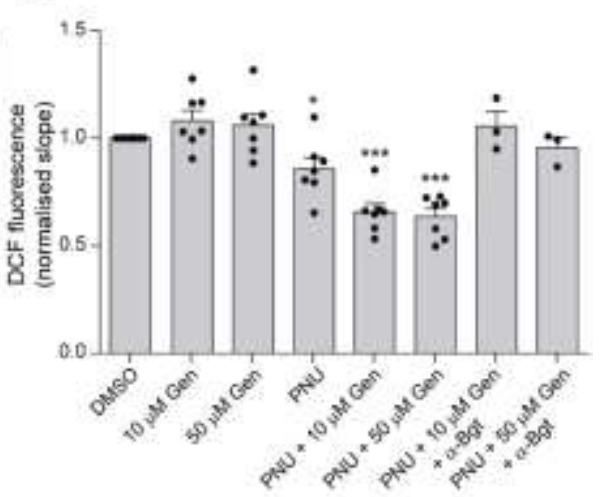




\section{TABLES}

Table 1. Pharmacological and kinetic effects of flavonoids on human $\alpha 7$ receptors expressed in Xenopus oocytes and in BOSC23 cells.

\begin{tabular}{|c|c|c|c|c|}
\hline & Protocol & Genistein & Quercetin & Neoflavonoid \\
\hline \multicolumn{5}{|c|}{ Macroscopic currents from $\alpha 7$ expressed in Xenopus oocytes } \\
\hline \multirow{2}{*}{$\mathrm{EC}_{50}(\mu \mathrm{M})$} & Co-app & $9.36 \pm 0.81$ & $15.39 \pm 2.03^{\# \#}$ & $9.64 \pm 0.66^{\text {\&\& }}$ \\
\hline & Pre + Co-app & $10.15 \pm 0.79$ & $11.45 \pm 0.52$ & $9.15 \pm 0.63$ \\
\hline \multirow{2}{*}{ Hill Slope } & Co-app & $2.98 \pm 0.34$ & $2.12 \pm 0.23$ & $3.16 \pm 0.34$ \\
\hline & Pre + Co-app & $2.53 \pm 0.20$ & $2.33 \pm 0.19$ & $4.04 \pm 0.58$ \\
\hline \multirow{2}{*}{$\begin{array}{c}\text { Max } \\
\text { Potentiation }\end{array}$} & Co-app & $2.08 \pm 0.09^{\star \star \star}$ & $2.13 \pm 0.07^{* \star *}$ & $1.46 \pm 0.03^{\star \star \star \# \# \# \& \& 8}$ \\
\hline & Pre + Co-app & $2.18 \pm 0.05^{\star * \star}$ & $2.30 \pm 0.14^{\star \star *}$ & $1.45 \pm 0.02^{* * * \# \# \& \& 8}$ \\
\hline \multirow{2}{*}{$\begin{array}{c}\% \operatorname{Max} \\
\text { Potentiation }\end{array}$} & Co-app & $208 \pm 9^{\star * *}$ & $213 \pm 7^{* * *}$ & $146 \pm 3^{\star \star \star}$ \\
\hline & Pre + Co-app & $218 \pm 5^{\star \star \star}$ & $230 \pm 14^{\star \star *}$ & $145 \pm 2^{\star \star \star}$ \\
\hline \multirow{2}{*}{$\mathrm{n}$} & Co-app & 11 & 8 & 10 \\
\hline & Pre + Co-app & 16 & 8 & 9 \\
\hline \multirow[b]{2}{*}{$\mathrm{N}$} & Co-app & 4 & 3 & 3 \\
\hline & Pre + Co-app & 4 & 3 & 3 \\
\hline \multicolumn{5}{|c|}{ Macroscopic currents from $\alpha 7$ expressed in BOSC23 cells } \\
\hline Current Peak (times) & Co-app & $1.38 \pm 0.28^{* *}$ & $1.25 \pm 0.17^{\star *}$ & $1.25 \pm 0.14^{\star \star *}$ \\
\hline Net Charge (times) & Co-app & $1.91 \pm 0.62^{* \star *}$ & $1.18 \pm 0.25$ & $1.86 \pm 0.30^{* *}$ \\
\hline Net Charge/Peak & Co-app & $1.45 \pm 0.61$ & $0.95 \pm 0.14$ & $1.51 \pm 0.34$ \\
\hline$\tau_{\text {fast }}(\mathrm{ms})$ & Co-app & $56 \pm 20$ & $61 \pm 32$ & $37 \pm 11$ \\
\hline$\tau_{\text {slow }}(\mathrm{ms})$ & Co-app & $728 \pm 218$ & $771 \pm 397$ & $1089 \pm 769$ \\
\hline $\mathrm{n}$ & Co-app & 8 & 7 & 7 \\
\hline $\mathrm{N}$ & Co-app & 4 & 4 & 4 \\
\hline
\end{tabular}

Top: Macroscopic currents recorded from Xenopus oocytes expressing human $\alpha 7$. ACh concentration: $30 \mu \mathrm{M}$. Values are mean \pm SEM. Data was estimated from concentration-response curves shown in Figure 1B. The maximal potentiation was calculated as ( $\left.\mathrm{I}_{\mathrm{ACh}} \mathrm{EC} 20+\mathrm{PAM}\right) / \mathrm{I}_{\mathrm{ACh} \text { EC20 }}$ and compared with the respective control current by two-tailed Student's t-test. Significant differences are indicated with the symbol * Statistical analysis among the different flavonoids was conducted using OneWay ANOVA followed by Bonferroni's post-hoc tests for multiple comparisons. The symbols \# and \& indicate significant differences comparing with Gen and Que, respectively. For all the cases, the number of symbols (one, two or three) indicates different significant $p$-values independently of the type of symbol (For instance, $p<0.05^{*}, p<0.01^{* *}$, $\left.p<0.001^{* *}\right)$. $N$ is the number of batches of oocytes used for experiments and $n$ corresponds to the number of independent experiments carried out, each from different oocytes.

Bottom: Macroscopic currents recorded from BOSC23 cells expressing human $\alpha 7$. ACh concentration: $100 \mu \mathrm{M}$. Values are mean \pm SD and they correspond to values relative 
to the control in the same cell (peak current and net charge) or absolute values (decay time constants, $\tau$ ) as described in Materials and Methods. Statistical analysis was conducted by two-tailed Student's t-test comparing with the respective control macroscopic current in absence of flavonoid $\left(p<0.05^{*}, p<0.01^{* *}, p<0.001^{* \star *}\right)$. $n$ corresponds to the number of independent experiments, each from different cell patches, and $\mathrm{N}$ indicates the number of cell transfections. 
Table 2. Single-channel parameters of $\alpha 7, \alpha 7-5 \mathrm{HT}_{3} \mathrm{~A}$ and $\alpha 7$ TSLMF receptors in the presence of flavonoids.

\begin{tabular}{|c|c|c|c|c|c|c|c|c|}
\hline Receptor & Flavonoid & $\begin{array}{c}\text { Flavonoid } \\
\text { concentration } \\
(\mu \mathrm{M})\end{array}$ & $\tau_{\text {open }}(\mathrm{ms})$ & $\begin{array}{c}\text { t-test for } \\
\tau_{\text {open }}\end{array}$ & $\tau_{\text {burst }}(\mathrm{ms})$ & $\begin{array}{c}\text { t-test for } \\
\tau_{\text {burst }}\end{array}$ & $\mathbf{n}$ & $\mathbf{N}$ \\
\hline \multirow{16}{*}{$\alpha 7$} & - & - & $0.27 \pm 0.01$ & - & $0.35 \pm 0.02$ & - & 5 & 5 \\
\hline & Genistein & 5 & $1.10 \pm 0.05^{\star \star \star}$ & $t(7)=-36.887$ & $3.21 \pm 0.26^{\star \star *}$ & $t(7)=-30.430$ & 4 & 3 \\
\hline & Genistein & 10 & $1.08 \pm 0.07^{* * *}$ & $t(7)=-27.384$ & $4.00 \pm 0.26^{\star * *}$ & $t(7)=-62.792$ & 4 & 3 \\
\hline & Genistein & 25 & $1.62 \pm 0.04^{* * *}$ & $t(7)=-65.784$ & $13.62 \pm 3.53^{* * *}$ & $\mathrm{t}(7)=-31.400$ & 4 & 3 \\
\hline & Genistein & 50 & $1.59 \pm 0.22^{\star \star \star}$ & $t(8)=-26.279$ & $12.24 \pm 3.75^{\star \star \star}$ & $t(8)=-27.586$ & 5 & 4 \\
\hline & Genistein & 100 & $1.54 \pm 0.17^{* * *}$ & $\mathrm{t}(8)=-31.600$ & $10.92 \pm 0.97^{* \star *}$ & $\mathrm{t}(8)=-72.828$ & 5 & 4 \\
\hline & Quercetin & 5 & $0.24 \pm 0.03$ & $t(7)=2.008$ & $0.31 \pm 0.06$ & $t(7)=1.436$ & 4 & 4 \\
\hline & Quercetin & 10 & $0.55 \pm 0.11^{*}$ & $t(7)=-5.687$ & $1.44 \pm 0.45^{*}$ & $t(7)=-5.556$ & 4 & 4 \\
\hline & Quercetin & 25 & $0.76 \pm 0.25^{\star \star \star}$ & $t(8)=-7.252$ & $2.89 \pm 1.12^{\star \star \star}$ & $t(8)=-5.068$ & 5 & 3 \\
\hline & Quercetin & 50 & $0.78 \pm 0.12^{\star \star \star}$ & $\mathrm{t}(7)=-15.252$ & $3.33 \pm 0.38^{\star * *}$ & $t(7)=-40.133$ & 4 & 3 \\
\hline & Quercetin & 100 & $0.76 \pm 0.04^{\star \star \star}$ & $t(7)=-23.996$ & $2.81 \pm 0.44^{*}$ & $t(7)=-12.557$ & 4 & 4 \\
\hline & Neoflavonoid & 5 & $0.27 \pm 0.12$ & $\mathrm{t}(7)=0.0182$ & $0.39 \pm 0.17$ & $t(7)=-0.545$ & 4 & 3 \\
\hline & Neoflavonoid & 10 & $0.25 \pm 0.10$ & $t(7)=0.458$ & $1.11 \pm 0.15^{*}$ & $t(7)=-11.585$ & 4 & 3 \\
\hline & Neoflavonoid & 25 & $0.54 \pm 0.10^{* \star *}$ & $t(7)=-8.769$ & $2.00 \pm 1.01^{*}$ & $t(7)=-3.717$ & 4 & 4 \\
\hline & Neoflavonoid & 50 & $0.57 \pm 0.06^{* \star *}$ & $t(7)=-11.277$ & $2.66 \pm 0.37^{\star \star \star}$ & $t(7)=-30.545$ & 4 & 4 \\
\hline & Neoflavonoid & 100 & $0.39 \pm 0.13$ & $t(7)=-2.022$ & $1.36 \pm 0.71^{*}$ & $t(7)=-3.220$ & 4 & 4 \\
\hline \multirow{4}{*}{$\alpha 7-5 \mathrm{HT}_{3} \mathrm{~A}$} & - & - & $5.26 \pm 0.30$ & - & $12.35 \pm 3.00$ & - & 5 & 4 \\
\hline & Genistein & 50 & $2.32 \pm 0.34^{\star \star \star}$ & $t(7)=13.812$ & $6.06 \pm 1.89^{\star \star}$ & $t(7)=4.237$ & 4 & 3 \\
\hline & Quercetin & 50 & $4.54 \pm 1.00$ & $t(8)=1.580$ & $10.36 \pm 2.08$ & $\mathrm{t}(8)=1.302$ & 5 & 3 \\
\hline & Neoflavonoid & 50 & $4.52 \pm 1.00$ & $t(7)=1.606$ & $13.21 \pm 3.73$ & $t(7)=-0.385$ & 4 & 3 \\
\hline \multirow{4}{*}{$\alpha 7$ TSLMF } & - & - & $1.26 \pm 0.43$ & - & $1.98 \pm 0.74$ & - & 5 & 4 \\
\hline & Genistein & 50 & $0.42 \pm 0.11^{* *}$ & $t(8)=4.195$ & $1.43 \pm 0.42$ & $t(8)=1.446$ & 5 & 4 \\
\hline & Quercetin & 50 & $1.28 \pm 0.30$ & $t(7)=-0.066$ & $1.69 \pm 0.67$ & $t(7)=0.607$ & 4 & 3 \\
\hline & Neoflavonoid & 50 & $0.77 \pm 0.04$ & $t(7)=2.239$ & $1.51 \pm 0.47$ & $t(7)=1.092$ & 4 & 3 \\
\hline
\end{tabular}

Single-channel currents were recorded from cells expressing human $\alpha 7$ wild-type (activated by $100 \mu \mathrm{M}$ ACh), $\alpha 7-5 \mathrm{HT}_{3} \mathrm{~A}$ (activated by $500 \mu \mathrm{M} \mathrm{ACh}$ ) or the quintuple mutant $\alpha 7$ TSLMF (activated by $100 \mu \mathrm{M}$ ACh) in the absence or presence of flavonoids. $\tau_{\text {open }}$ and $\tau_{\text {burst }}$ correspond to the slowest components of the corresponding histograms. Values are mean \pm SD. $n$ : number of independent experiments, each from different cell patches. N: number of cell transfections. Statistical significance was determined by comparing the mean value in the presence of the flavonoid respect to the mean value in absence of the flavonoid by two-tailed Student's t-test. The resulting t-values are shown in the Table and $p$-values are indicated as $p<0.05^{\star}, p<0.01^{\star *}, p<0.001^{* \star *}$. 